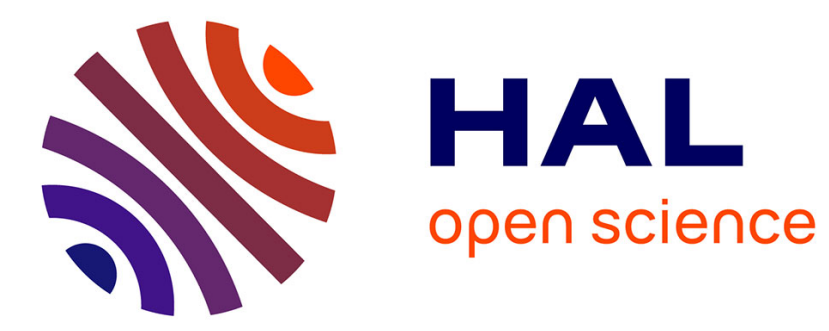

\title{
Ab initio diabatic and adiabatic calculations for francium hydride $\mathrm{FrH}$
}

Hanen Souissi, Leila Mejrissi, Héla Habli, Maarib Alsahhaf, Brahim Oujia, Florent X. Gadéa

\section{- To cite this version:}

Hanen Souissi, Leila Mejrissi, Héla Habli, Maarib Alsahhaf, Brahim Oujia, et al.. Ab initio diabatic and adiabatic calculations for francium hydride FrH. New Journal of Chemistry, 2020, 44 (14), pp.55725587. 10.1039/C9NJ06391A . hal-02899709

\section{HAL Id: hal-02899709 \\ https://hal.science/hal-02899709}

Submitted on 14 Dec 2020

HAL is a multi-disciplinary open access archive for the deposit and dissemination of scientific research documents, whether they are published or not. The documents may come from teaching and research institutions in France or abroad, or from public or private research centers.
L'archive ouverte pluridisciplinaire HAL, est destinée au dépôt et à la diffusion de documents scientifiques de niveau recherche, publiés ou non, émanant des établissements d'enseignement et de recherche français ou étrangers, des laboratoires publics ou privés. 


\section{Accepted Manuscript}

This article can be cited before page numbers have been issued, to do this please use: H. Souissi, L. mejrissi, H. Habli, M. alsahhaf, B. Oujia and F. X. Gadea, New J. Chem., 2020, DOI: 10.1039/C9NJ06391A.

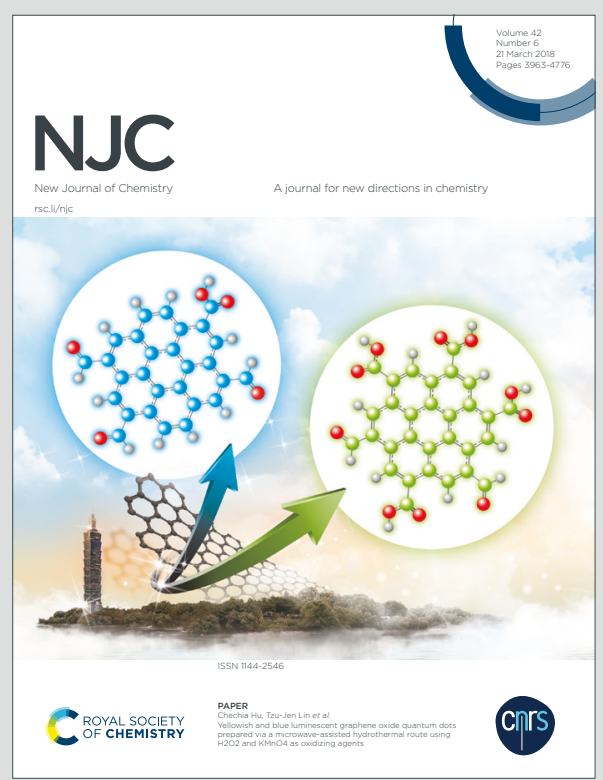

This is an Accepted Manuscript, which has been through the Royal Society of Chemistry peer review process and has been accepted for publication.

Accepted Manuscripts are published online shortly after acceptance, before technical editing, formatting and proof reading. Using this free service, authors can make their results available to the community, in citable form, before we publish the edited article. We will replace this Accepted Manuscript with the edited and formatted Advance Article as soon as it is available.

You can find more information about Accepted Manuscripts in the Information for Authors.

Please note that technical editing may introduce minor changes to the text and/or graphics, which may alter content. The journal's standard Terms \& Conditions and the Ethical guidelines still apply. In no event shall the Royal Society of Chemistry be held responsible for any errors or omissions in this Accepted Manuscript or any consequences arising from the use of any information it contains. 


\title{
Ab initio diabatic and adiabatic calculation for the francium hydride FrH
}

Hanen Souissia,, ${ }^{\text {, }}$ Leila Mejrissia, Hela Hablia, Maarib Alsahhaf ${ }^{b}$, Brahim Oujia ${ }^{c}$ et Florent Xavier Gadéa $^{\mathrm{d}}$

a Laboratoire de Physique Quantique, Faculté des Sciences de Monastir, Université of Monastir, Avenue de l'Environnement 5019, Monastir, Tunisie.

b Physics Department, Faculty of Science, Princess Nourah bint abdulrahman University, Riyadh-Kingdom of Saudi Arabia.

${ }^{\mathrm{c}}$ University of Jeddah, Faculty of Science, Physics Department, Jeddah, Kingdom of Saudi Arabia,

${ }^{d}$ Laboratoire de Chimie et Physique Quantique, UMR5626 du CNRS, Université de Toulouse, UPS, 118 route de Narbonne, 31062, Toulouse Cedex 4, France.

(*) E-mail : hanensouissi9@gmail.com

\begin{abstract}
Explicitly ab-initio diabatic and adiabatic calculations of potential energy curves (PECs) of the states ${ }^{1,3} \Sigma^{+}, 1,3 \Pi$, and ${ }^{1,3} \Delta$ of francium hydride $\mathrm{FrH}$ have been carried out with several approaches. We determined for both representations, the Permanent and Transition Dipole Moment (PDM and TDM) and the vibrational levels. The calculation was based on the Configuration Interaction (CI) method, which includes the Effective Core Potentials (ECP) and Core Polarization Potentials (CPP). The FrH system is considered as an effective two-electron system, permitting calculation of structural and electronic properties with Full Configuration Interaction (FCI). For the diabatisation method, we perform an efficient diabatization approach, which depends on the variational effective Hamiltonian theory (VEH) and a dynamic overlap matrix. This work finishes the diabatic and adiabatic ab-initio spectroscopic investigations of all the alkali hydrides series. In addition, we present our adiabatic results of FrH by comparing it with the other alkali hydrides systems ( $\mathrm{Li}-\mathrm{Cs}) \mathrm{H}$. This study is essential for a wide range of theoretical and experimental work.
\end{abstract}

\section{I- Introduction}

Many theoretical ${ }^{1-24}$ and experimental ${ }^{25-31}$ researchers have studied the alkali-metal hydrides for many years. The investigation of the chemistry compounds in the early universe and the resolution of the abundances of these compounds in stellar atmospheres needed a thorough understanding of the cross sections for many collisional processes ${ }^{17}$. For example, inelastic collisions between alkali-metal atoms ( $\mathrm{Li}$ and $\mathrm{Na}$ ) and hydrogen ${ }^{32,33}$, radiative charge transfer 
between alkali-metal atoms and $\mathrm{H}^{+34}$, neutralization collisions between $\mathrm{H}^{-}$and alkali ion 130 35,36cle Online or dissociative recombination ${ }^{37}$. Adopting the ideas of ref. ${ }^{38}$ concerning the manipulating molecules via combined laser and static fields, alkali-metal hydrides could be a beneficial for such experiments.

Interestingly, the francium

is the heaviest alkali-metal atom. Further, the francium exists only thirty grams in the earth crust. It is the longest-lived isotope lasts only 20 minutes and it is the most unstable element of the first 103 in the periodic table. The francium gives a sensible test of the influence of Quantum and relativistic Electro-dynamic effects on the atomic composition ${ }^{39}$. In addition, the francium is also a very good compound for examining feeble interactions in atoms, for example atomic Parity Non-Conservation (PNC) ${ }^{\mathbf{4 0 - 4 2}}$. One of the most important discoveries of the 1939s was the francium by Perey of the curie institute located in Paris by observing the $\beta$ decay of ${ }^{223} \mathrm{Fr}$ in the natural actinium radioactive decay chain ${ }^{43}$. All its isotopes have short half-lives (maximum $21.8 \mathrm{~min}$, for ${ }^{223} \mathrm{Fr}$ ), that is why this element was the second-most rare natural compound on earth after astate 'At'44-45. It was not until 1978 that the group guided by Sylvan Liberman at ISOLDE in CERN manage to find the D2 resonant line of the spectrum of Fr, leading the way for many spectroscopic investigations. Meanwhile, the evolution of tunable lasers had allowed the trapping and cooling of alkali atoms involving resonance light in combination with magnetic fields, indeed all the parts obligatory for cooling and trapping francium were there at Stony Brook in the early $1990 \mathrm{~s}^{44}$. Indeed, this rarity is due to its transient existence, as a decay product of actinium ${ }^{46}$. The main cause of the order of the francium of the least studied element is the experimental difficulties ${ }^{\mathbf{4 0}} \mathbf{4 7}$. The francium is never found outside nuclear facilities or research laboratories, being potentially dangerous because of its intense radioactivity and its natural occurrence in uranium mineral but at any one time, there is one francium atom per one billion atoms of uranium ${ }^{48}$. When the rats were injected with francium, it concentrated in the bladder, gut, kidneys, saliva and liver. In those rats with cancer, it also concentrated in the tumor, raising hopes that francium might have medical uses in treating this disease. For reasons given below, this was a forlorn hope ${ }^{49}$.

The topic of this work is to investigate the electronic, vibrational and dipolar electric properties for the francium hydride system including: (i) the PECS of several symmetries ${ }^{1,3} \Sigma^{+},{ }^{1,3} \Pi$, and ${ }^{1,3} \Delta$ and their spectroscopic constants $\left(R_{e}\right.$ : Equilibrium distance, $D_{e}$ : Well depth, $T_{e}$ : Transition energies, $\omega_{e} \chi_{e}$ : Anharmonic constant, $\omega_{e}$ : vibrational constant and $B_{e}$ : rotational constant). (ii) The vibrational properties. (iii) The PDM and TDM functions. 
As we know that there are no previous experimental studies have yet been published forievthercle Online FrH molecule and there is two theoretical adiabatic studies have been examined by Hill et al. ${ }^{1}$ and Noro et al. ${ }^{2}$ using the new correlation consistent (cc) basis sets. So, this method is based on Pseudo-Potential (PP) Hamiltonian, which is contracted from double to quintuple Zeta quality. Moreover, for these alkali-metal, the Gaussian-type function sets have been contracted by application the two approach which are the exact 2-component (X2C) scalar relativistic Hamiltonians $^{50-55}$ and third-order Douglas-Kroll-Hess (DK3) approximation ${ }^{56}$. In addition, we compare our results with the other alkali hydrides systems (Li-Cs) $\mathrm{H}^{3-7}$. In 2006, Aymar et al. ${ }^{49}$ have studied the electronic structure of $\mathrm{Fr}_{2}, \mathrm{FrRb}$ and FrCs molecules and their cations. Then, in 2008, J. Deiglmar et al. ${ }^{57}$ have studied the $\mathrm{Fr}_{2}$ molecule. These results are useful for further theoretical and experimental researches in spectroscopy or collision fields.

This work is outlined as follows: Section II introduces our methodology based on ab-initio diabatic and adiabatic calculation. In Section III, we present the molecular diabatic and adiabatic PECs, their spectroscopic constants together and the vibrational level properties. In section IV, we give our numerical data of the permanent and transition dipole moments (PDM and TDM) for both representation. Section V contains the conclusions.

\section{II-Ab inito calculations}

\section{Calculation Details}

Many studies have focused on the electronic structure by using ab initio method of alkali-metal hydrides ${ }^{3,7,13,14}$. In this calculation, the polarizable core of $\mathrm{Fr}^{+}$is substituted by a semi-empirical pseudo-potential put forward by Barthelat and Durand ${ }^{\mathbf{5 8}, \mathbf{5 9}}$, completed by both approach Core Polarization Potentials and Effective Core Potentials. The semi-local form of the Fr core is taken from the paper studied by M. Aymar et al. ${ }^{49}$. In this framework, the electronic properties were investigated first at the Self-Consistent Field (SCF) based on Full Configuration Interaction (FCI) applicated the Toulouse package code 3-7, 13, 14, 60-79. Moreover, the interaction between the polarizable core $\mathrm{Fr}^{+}$with the hydrogen nucleus and the valence electrons is treated using the core polarization potential $\mathrm{V}_{\mathrm{CPP}}$ given by Müller et al. ${ }^{\mathbf{8 0}}$ which is written as:

$$
V_{C P P}=-\frac{1}{2} \sum_{\gamma} \alpha_{\gamma} \overrightarrow{f_{\gamma}^{\prime}} \overrightarrow{f_{\gamma}}
$$

Where $\alpha_{\gamma}$ is the $\gamma$ core's dipole polarizability and $\overrightarrow{f_{\gamma}}$ represents the electrostatic field proposed by the other cores on the $\gamma$ and the valence electron: 


$$
\overrightarrow{f_{\gamma}}=\sum_{i} \frac{\vec{R}_{\gamma^{i}}}{R_{\gamma^{\prime} i}^{3}} F_{l}\left(R_{\gamma^{\prime}}, \rho_{\gamma}^{l}\right)-\sum_{\gamma^{\prime} \neq \gamma} Z_{c} \frac{\vec{R}_{\gamma^{\prime} \gamma}}{R_{\gamma^{\prime} \gamma}^{3}}
$$

$\vec{R}_{\gamma i}$ is the core-electron vector, the $\vec{R}_{\gamma^{\prime} \gamma}$ vector is the core-core and $F_{1}\left(R_{\gamma i}, \rho_{\gamma}\right)$ is the cut-off operator corresponding to the operator expression of Foucault et al. ${ }^{\mathbf{8 1}}$, which is written as follows:

$$
F\left(R_{\gamma i}, \rho_{\gamma}\right)= \begin{cases}0 ; & R_{\gamma i}<\rho_{\gamma} \\ 1 ; & R_{\gamma i}>\rho_{\gamma}\end{cases}
$$

Furthermore, the cut-off radius is given by a function of (l) according to:

$$
F\left(R_{\gamma i}, \rho_{\gamma}\right)=\sum_{l=0}^{\infty} \sum_{m=-l}^{+1} F_{l}\left(R_{\gamma i}, \rho_{\gamma}\right)|\operatorname{lm} \gamma\rangle\langle\operatorname{lm} \gamma|
$$

$|\operatorname{lm} \gamma\rangle\langle\operatorname{lm} \gamma|$ is a spherical harmonic in the center of the $\gamma$ core.

In this framework, the core polarizability of the francium is taken from Ref. ${ }^{\mathbf{8 2}}$ where $\alpha_{\mathrm{Fr}}=20.38$ $a_{0}^{3}$. The optimized cut-off parameters are $\rho_{\mathrm{s}}=3.1629, \rho_{\mathrm{p}}=3.027$ and $\rho_{\mathrm{d}}=3.1068 \mathrm{Bohr}$.

To have a best representation of the atomic levels $(7 \mathrm{~s}, 7 \mathrm{p}, 6 \mathrm{~d}, 8 \mathrm{~s}, 8 \mathrm{p}, 7 \mathrm{~d}, 9 \mathrm{~s}$ and $9 \mathrm{p})$ of the Fr atom, we optimized a large Gaussian-Type Orbital (GTO) basis set 8s/6p/5d (see Table $\mathbf{S 1}$ in the supporting information). While for the hydrogen atom, we have re-optimized the basis set studied by Zrafi et al. ${ }^{7}$ to be $(7 \mathrm{~s} / 3 \mathrm{p} / 2 \mathrm{~d})$. Therefore, we have improved the variation between our result and the experimental one, which is less than $47 \mathrm{~cm}^{-1}$ for 1s level (see Table S2 in the supporting information).

Our selection of the basis set globally ameliorates the investigated francium atomic level energies compared with preceding works like the work of Aymar et al. ${ }^{49}$ on the francium atom. In Table S3, we display the atomic spectrum of Fr of our work and those of Aymar et al. ${ }^{49}$ which are compared with the experimental ones ${ }^{83}$. The analysis of the experimental and our theoretical energies shows a good concordance between them ${ }^{\mathbf{8 3}}$ where the largest difference is $88 \mathrm{~cm}^{-1}$. We display in Table S4, our energies of the asymptotic limits with the experimental ones, which dissociate bellow the ionic limit $\left(\mathrm{Fr}^{+}+\mathrm{H}^{-}\right)$. This limit is described as $\mathrm{IP}_{\mathrm{Fr}}-\mathrm{EA}_{\mathrm{H}}$ where $\operatorname{IP}_{\mathrm{Fr}}\left(=32848 \mathrm{~cm}^{-1}\right)$ is the ionization potential of the francium and $\mathrm{EA}_{\mathrm{H}}\left(=6083 \mathrm{~cm}^{-1}\right)$ is 
the electronic affinity of hydrogen. Our values are in very good accord with the experimierttafcle Online data. In addition, we can see in Table $\mathbf{S 4}$ that the relative errors between the experimental and theoretical energies do not exceed $0.094 \%$.

\section{Diabatic Calculation Details}

We used here the same method used for full alkali hydride series $\left(\mathrm{LiH}^{3}, \mathrm{NaH}^{4}, \mathrm{KH}^{5}, \mathrm{RbH}^{6}\right.$, $\left.\mathrm{CsH}^{7}\right)$, the alkaline earth hydride $\left(\mathrm{CaH}^{+65}\right)$ and mixed alkali $\left(\mathrm{KLi}^{70}\right.$ and $\left.\mathrm{RbLi}^{72}\right)$. The strategy of the diabatisation method is to determine theoretical approximation of the non-adiabatic coupling between the pertinent adiabatic states and to make it disappear by a suitable unitary transformation relative to Variational Effective Hamiltonian theory (VEH) ${ }^{\mathbf{8 4}}$. In the actual performance of the VEH at each distance the target space (adiabatic states, $\Psi_{\mathrm{i}}$ ) and the model space (reference states, $\Phi_{i}$ ) need to be exactly defined now.

The model space noted $\mathrm{S}_{0}$ is crossed by $\mathrm{n}$ orthogonal vectors $\left\{\left|R_{i}\right\rangle, i=1, \ldots n\right\}$. The associated projector is $\mathrm{P}_{\mathrm{o}}$ :

$$
P_{S_{0}}=P_{0}=\sum_{i=1}^{n}\left|R_{i}\right\rangle\left\langle R_{i}\right|
$$

In this work we choose the large inter-atomic distance interval used in the adiabatic work where all inter-atomic interaction disappears.

The target space $\mathrm{S}$ is clearly formed by the " $\mathrm{n}$ " adiabatic functions " $\Psi_{\mathrm{i}}$ " at inter-atomic distance "R" and the projector "P":

$$
P=\sum_{i=1}^{n}\left|\Psi_{i}\right\rangle\left\langle\Psi_{i}\right|
$$

Moreover, the projection matrix of the model space vectors on the target space is made unitary

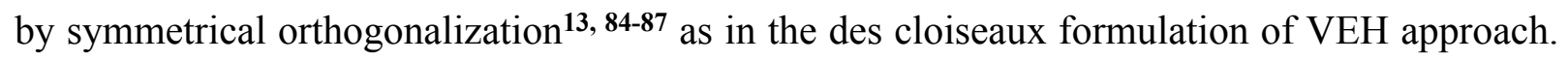
First, we used an effective overlap matrix A that defined as following:

$$
\mathrm{Aij}=\left\langle\mathrm{R}_{\mathrm{i}} \mid \mathrm{P}_{0} \Psi_{\mathrm{j}}\right\rangle=\left\langle\Psi_{\mathrm{i}} \mid\right\rangle
$$

Then, the $n$ diabatic states $\left(D_{i}\right)$ are orthonormal linear combinations of the " $n$ " adiabatic states, which the matrix formulation is written as:

$$
\mathrm{Uij}=\left\langle\Psi_{i} \mid \mathrm{D}_{j}\right\rangle, \quad \mathrm{U}^{\prime} \mathrm{U}=\mathbb{1}
$$

Since the matrix diagonal of the electronic Hamiltonian $(\mathrm{H})$ in the adiabatic representation be noted as:

$$
\mathrm{E}=\left\langle\Psi_{\mathrm{i}}|\mathrm{H}| \Psi_{\mathrm{j}}\right\rangle=\mathrm{E}_{\mathrm{i}} \delta_{\mathrm{ij}}
$$


It is "de-diagonalised" in the diabatic representation where $\mathrm{H}$ is now written $\mathrm{U} \cdot \mathrm{E} U$ View Article Online As mentioned in the paper of Romero et al. ${ }^{\mathbf{8 6}}$, in all dibatisation procedures, the interference between a molecular orbital at a specified point (named R) and another specified point (named $\mathrm{R}_{0}$ ) plays a key role. Moreover, the overlap matrix A depends on the movement of the atoms when passing from $\mathrm{R}$ to $\mathrm{R}_{0}$. The choice of the lower half diagonal section from one distance and the superior section from the another distance for a diatomic molecule, related to fix the common origin of coordinates in one of the atoms precisely at the heavier and assuming a diagonal $\mathbb{1}$ matrix in each of the diagonal blocks. In a way to reduce the remaining coupling between the quasi-diabatic states, from A the unitary adiabatic-diabatic transformation matrix $\mathrm{U}$ is making as:

$$
\mathrm{U}=\mathrm{A}\left(\mathrm{A}^{\prime} \mathrm{A}\right)^{-\frac{1}{2}}
$$

The Hamiltonian " $\mathrm{H}$ " in the diabatic basis is obtained as:

$$
\langle\mathrm{D}|\mathrm{H}| \mathrm{D}\rangle=\mathrm{U}^{\prime} \mathrm{EU}=\left(\mathrm{A}^{\prime} \mathrm{A}\right)^{-\frac{1}{2}} \mathrm{~A}^{\prime} \mathrm{E} \mathrm{A}\left(\mathrm{A}^{\prime} \mathrm{A}\right)^{-\frac{1}{2}}
$$

\section{III- Results and interpretation}

\section{Adiabatic and diabatic PECs and their Spectroscopic constants}

In our study, we realize an adiabatic and diabatic calculation of the francium hydride by employing the pseudo-potential for the Fr core supplemented by CPP, ECP, FCI and the method of diabatisation. We investigated the PECs for various states of ${ }^{1,3} \Sigma^{+}, 1,3 \Pi$, and ${ }^{1,3} \Delta$ symmetries beneath the ionic limit $\left(\mathrm{Fr}^{+}+\mathrm{H}^{-}\right)$for both representations. These curves are shown in Figures 1-7 for a large number of grid points with $\mathrm{R}$ varying from 2.5 to 200 a.u. The PECS are investigated by FCI, which have been used to derive the spectroscopic constants of whole the states via Nvib program (The program is restricted to the harmonic expression of the vibrational problem (i.e. just the quadratic force field)). The obtained spectroscopic parameters are reported in Table 1.

\begin{tabular}{|c|c|c|c|c|c|c|}
\hline States & $\mathrm{R}_{\mathrm{e}}$ (a.u.) & $\mathrm{D}_{\mathrm{e}}\left(\mathrm{cm}^{-1}\right)$ & $\mathrm{T}_{\mathrm{e}}\left(\mathrm{cm}^{-1}\right)$ & $\omega_{\mathrm{e}}\left(\mathrm{cm}^{-1}\right)$ & $\omega_{\mathrm{e}} \chi_{\mathrm{e}}\left(\mathrm{cm}^{-1}\right)$ & $\mathrm{B}_{\mathrm{e}}\left(\mathrm{cm}^{-1}\right)$ \\
\hline \multicolumn{7}{|c|}{ (a) ${ }^{1} \Sigma^{+}$States } \\
\hline $\mathrm{X}^{1} \Sigma^{+}$ & 4.43 & 14041 & 0 & 802 & 1.34 & 0.31 \\
\hline $\mathrm{A}^{1} \Sigma^{+}$ & 7.31 & 9842 & 19572 & 211 & 4.04 & 0.07 \\
\hline $\mathrm{C}^{1} \Sigma^{+}$ & 5.65 & 2566 & 28433 & 47 & 1.34 & 0.01 \\
\hline $2^{\text {nd }} \min$ & 14.14 & 2278 & & & & \\
\hline $\mathrm{D}^{1} \Sigma^{+}$ & 6.06 & 588 & $34 \overline{1} 97$ & $\overline{94}$ & $0 . \overline{7} 4$ & $0 . \overline{0} 3$ \\
\hline $2^{\text {nd }} \min$ & 18.07 & 3214 & & & & \\
\hline $\mathrm{E}^{1} \Sigma^{+}$ & 5.76 & 1302 & $37 \overline{1} 56$ & 22 & $0 . \overline{8} 0$ & $0 . \overline{0} 1$ \\
\hline $2^{\text {nd }} \min$ & 14.32 & 3383 & & & & \\
\hline
\end{tabular}

Table 1. Spectroscopic constants for ${ }^{1,3} \Sigma^{+}, 1^{1,3} \Pi$ and ${ }^{1,3} \Delta$ states of FrH. 


\begin{tabular}{|c|c|c|c|c|c|c|}
\hline $\begin{array}{c}\mathrm{F}^{1} \Sigma^{+} \\
2^{\text {nd }} \min \\
\mathrm{G}^{1} \Sigma^{+} \\
2^{\text {nd }} \min \\
3^{\text {th }} \min \\
\mathrm{I}^{1} \Sigma^{+} \\
\end{array}$ & $\begin{array}{c}5.79 \\
9.69 \\
6.20 \\
8.65 \\
38.65 \\
7.72 \\
\end{array}$ & $\begin{array}{c}886 \\
1372 \\
596 \\
1408 \\
1271 \\
374 \\
\end{array}$ & $\begin{array}{c}38445 \\
40 \overline{2} 89 \\
- \\
44 \overline{2} 89 \\
\end{array}$ & $\begin{array}{l}20 \\
\overline{2} \\
- \\
1 \overline{4} 9 \\
\end{array}$ & $\begin{array}{c}0.41 \\
0 . \overline{14} \\
- \\
5 . \overline{9} 5 \\
\end{array}$ & $\begin{array}{c}0.01 \text { View Antic } \\
\text { DOI: } 10.1039 / \mathrm{C} 9 \mathrm{NJ} \\
0 . \overline{0} 1 \\
- \\
5 . \overline{7} 5 \\
\end{array}$ \\
\hline \multicolumn{7}{|c|}{ (b) ${ }^{3} \Sigma^{+}$States } \\
\hline $\begin{array}{c}\mathrm{a}^{3} \Sigma^{+} \\
\mathrm{c}^{3} \Sigma^{+} \\
2^{\text {nd }} \min \\
\mathrm{d}^{3} \Sigma^{+} \\
2^{\text {nd }} \min \\
\mathrm{e}^{3} \Sigma^{+} \\
2^{\text {nd }} \min \\
\mathrm{f}^{3} \Sigma^{+} \\
2^{\text {nd }} \min \\
\mathrm{g}^{3} \Sigma^{+} \\
2^{\text {nd }} \min \\
3^{\text {th }} \min \\
\mathrm{h}^{3} \Sigma^{+} \\
\mathrm{i}^{3} \Sigma^{+} \\
\end{array}$ & $\begin{array}{c}10.63 \\
5.43 \\
16.75 \\
5.98 \\
14.48 \\
5.30 \\
8.87 \\
5.74 \\
8.24 \\
5.00 \\
7.26 \\
25.0 \\
6.43 \\
6.55 \\
\end{array}$ & $\begin{array}{c}110 \\
52 \\
31 \\
2472 \\
17 \\
1442 \\
123 \\
125 \\
606 \\
939 \\
789 \\
49 \\
580 \\
714\end{array}$ & $\begin{array}{l}16601 \\
27890 \\
33 \overline{9} 49 \\
36 \overline{1} 08 \\
38 \overline{1} 82 \\
40 \overline{2} 17 \\
- \\
41 \overline{2} 56 \\
43199 \\
\end{array}$ & $\begin{array}{c}54 \\
175 \\
2 \overline{6} 6 \\
1 \overline{6} 8 \\
2 \overline{7} 7 \\
6 \overline{0} 7 \\
- \\
2 \overline{9} 2 \\
261\end{array}$ & $\begin{array}{c}6.90 \\
37.5 \\
4 \overline{0.5} \\
4 \overline{9} .4 \\
4 \overline{7} .7 \\
1 \overline{69} .9 \\
- \\
5 \overline{5.97} \\
31.31 \\
\end{array}$ & $\begin{array}{c}0.13 \\
2.61 \\
3 . \overline{16} \\
3 . \overline{9} 8 \\
3 . \overline{4} 9 \\
2 \overline{-} .23 \\
- \\
3 . \overline{8} 7 \\
1.28\end{array}$ \\
\hline \multicolumn{7}{|c|}{ (c) ${ }^{1,3} \Pi$ States } \\
\hline $\begin{array}{l}\mathrm{B}^{1} \Pi \\
\mathrm{b}^{3} \Pi \\
1^{1} \Pi \\
1^{3} \Pi \\
2^{1} \Pi \\
2^{3} \Pi \\
3^{1} \Pi \\
3^{3} \Pi \\
\end{array}$ & $\begin{array}{l}6.15 \\
5.71 \\
6.56 \\
5.15 \\
6.16 \\
6.04 \\
6.23 \\
5.84 \\
\end{array}$ & $\begin{array}{c}546 \\
787 \\
330 \\
1620 \\
574 \\
624 \\
571 \\
682 \\
\end{array}$ & $\begin{array}{l}27974 \\
27723 \\
31389 \\
29156 \\
38072 \\
37997 \\
39142 \\
38724 \\
\end{array}$ & $\begin{array}{l}184 \\
236 \\
145 \\
308 \\
194 \\
214 \\
190 \\
229 \\
\end{array}$ & $\begin{array}{l}20.61 \\
22.96 \\
21.13 \\
11.97 \\
20.82 \\
24.62 \\
19.29 \\
27.99 \\
\end{array}$ & $\begin{array}{l}0.77 \\
0.72 \\
1.03 \\
0.24 \\
0.68 \\
0.96 \\
0.51 \\
1.24 \\
\end{array}$ \\
\hline \multicolumn{7}{|c|}{ (d) ${ }^{1,3} \Delta$ States } \\
\hline $\begin{array}{l}1^{1} \Delta \\
1^{3} \Delta \\
2^{1} \Delta \\
2^{3} \Delta\end{array}$ & $\begin{array}{l}6.26 \\
6.22 \\
6.17 \\
6.16 \\
\end{array}$ & $\begin{array}{l}460 \\
471 \\
559 \\
561 \\
\end{array}$ & $\begin{array}{l}31102 \\
31069 \\
39082 \\
39075\end{array}$ & $\begin{array}{l}181 \\
185 \\
197 \\
198 \\
\end{array}$ & $\begin{array}{l}23.47 \\
23.77 \\
22.21 \\
22.47 \\
\end{array}$ & $\begin{array}{l}1.01 \\
1.02 \\
0.79 \\
0.81 \\
\end{array}$ \\
\hline
\end{tabular}

\section{1. ${ }^{1} \Sigma^{+}$Symmetry}

The adiabatic PECS for the ${ }^{1} \Sigma^{+}$molecular states of FrH are graphically depicted in Figure 1.

These curves have the same shape like those of $\mathrm{LiH}^{3}, \mathrm{NaH}^{4}, \mathrm{KH}^{5}, \mathrm{RbH}^{6}$ and $\mathrm{CsH}^{7}$. Therefore, the potential well of the ground state was practically profound at a short inter-nuclear distance $R_{e}=4.43 \mathrm{a} . \mathrm{u}$, which has a depth $\mathrm{D}_{\mathrm{e}}=14041 \mathrm{~cm}^{-1}$. The first excited state $\mathrm{A}^{1} \Sigma^{+}$presents a flat potential well explained by the largeness of the avoided crossing between the repulsive section of the $\mathrm{X}^{1} \Sigma^{+}$curve at the short distance and the attractive part of $\mathrm{A}^{1} \Sigma^{+}$about $\mathrm{R}=17$ a.u. In addition, the next excited state $\left(\mathrm{C}^{1} \Sigma^{+}\right)$, shows two minimum; the first is at about $\mathrm{R}=5.65$ a.u., and the second is at about $\mathrm{R}=14.14$ a.u., following the neutral-ionic avoided crossing with $\mathrm{A}^{1} \Sigma^{+}$ 


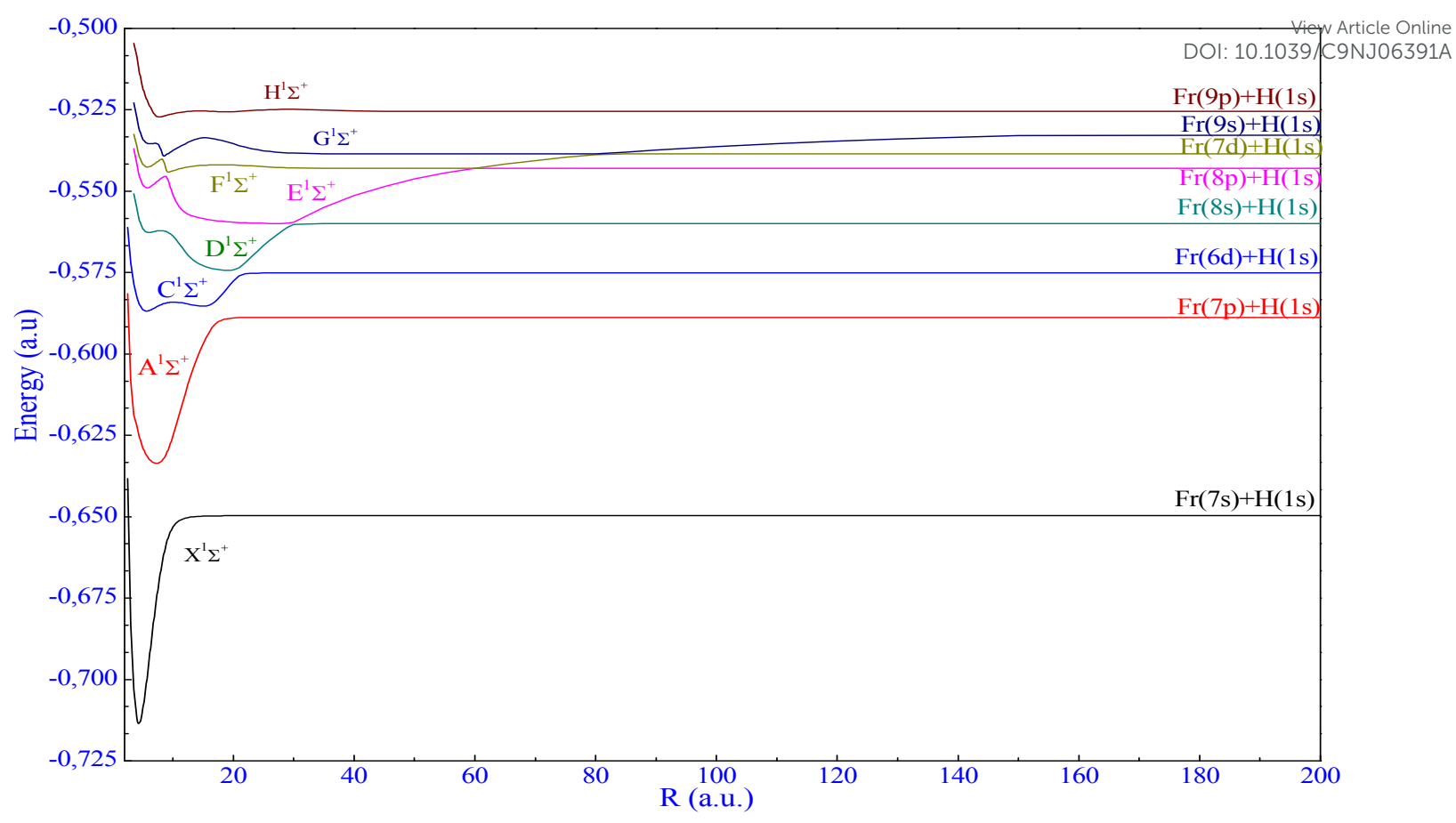

Figure 1. Adiabatic PECs ${ }^{1} \Sigma^{+}$dissociating below the ionic limit $\mathrm{Fr}^{+}+\mathrm{H}^{-}$.

For the most excited states, we can note that the appearance of double and triple wells. We can see that the D, E and F states shows double minima: The first one at a short distance that could be corresponding to an avoided crossing between neutral-neutral states, and the second at large distance corresponding to the ionic-neutral states and only the $\mathrm{G}^{1} \Sigma^{+}$have a triple minima.

As far as we know, the theoretical values are obtainable only for the ground state studied by Hill and al. ${ }^{1}$ and Noro et al. ${ }^{2}$. The MOLPRO procedure of $a b$ initio programs was used for all computation in their works. As seen in Table 2, we have listed the two available theoretical spectroscopic constants, which are studied with a different basis. Notably, our results correlate with Hill et al. ${ }^{1}$ data for the basis of cc-pV5Z-PP for $D_{e}$, where the difference less than $75 \mathrm{~cm}^{-1}$. Moreover, we can see that the equilibrium distances $\mathrm{R}_{\mathrm{e}}$ got by Noro et al. ${ }^{2}$ for the basis of wCVQZ-DK3 is larger than our results around 0.4 a.u. 
Table 2. Main spectroscopic constant for the ground state of the molecules FrH.

\begin{tabular}{|c|c|c|c|}
\hline Basis sets & $\mathbf{R}_{\mathbf{e}}$ (a.u.) & $\mathbf{D}_{\mathbf{e}}\left(\mathbf{c m}^{\mathbf{- 1}}\right)$ & $\left.\boldsymbol{\omega}_{\mathbf{e}} \mathbf{( c m}^{-1}\right)$ \\
\hline This work & 4.43 & 14041 & 802 \\
\hline Dzp $^{1}$ & 4.943 & - & 833 \\
\hline Tzp $^{1}$ & 4.858 & - & 902 \\
\hline Qzp $^{1}$ & 4.849 & - & 901 \\
\hline cc-pVDZ-PP1 $^{1}$ & 5.157 & 11171 & 811 \\
\hline cc-pVTZ-PP1 $^{1}$ & 5.119 & 13378 & 836 \\
\hline cc-pVQZ-PP1 $^{1}$ & 5.128 & 13955 & 833 \\
\hline cc-pV5Z-PP $^{1}$ & 5.134 & 14116 & 828 \\
\hline CBS $^{1}$ & 5.142 & 14228 & 823 \\
\hline wCVDZ-DK3 $^{2}$ & 4.941 & 10710 & 846 \\
\hline wCVTZ-DK3 $^{2}$ & 4.854 & 12892 & 885 \\
\hline wCVQZ-DK3 $^{2}$ & 4.840 & 13455 & 893 \\
\hline
\end{tabular}

We list in Table 3 the positions of some avoided crossings, which were located in the PECS with the corresponding main energy difference for the FrH. Similarly to the alkali hydrides series $^{3-7}$, these crossings corresponding to the excitation or charge transfer efficiency between the $\mathrm{Fr}$ and $\mathrm{H}$ atoms and the presence of numerous avoided crossings at a short and a long distance come from the unusual undulating behavior of $(-1 / \mathrm{R})$. In this framework, these crossings are accountable for the particular behaviors of PECs such as the presence of multiple wells as for $\mathrm{G}^{1} \Sigma^{+}$and the appearance of a wave feature in PECs.

Table 3. Avoided crossing positions and energy difference between two states.

\begin{tabular}{|c|c|c|}
\hline States & Positions (a.u.) & $\Delta \mathrm{E}\left(\mathrm{cm}^{-1}\right)$ \\
\hline $\mathrm{X}^{1} \Sigma^{+} / \mathrm{A}^{1} \Sigma^{+}$ & 10.5 & 6575.5 \\
\hline $\mathrm{A}^{1} \Sigma^{+} / \mathrm{C}^{1} \Sigma^{+}$ & 17 & 1512.18 \\
\hline $\mathrm{C}^{1} \Sigma^{+} / \mathrm{D}^{1} \Sigma^{+}$ & 21 & 531.57 \\
\hline $\mathrm{D}^{1} \Sigma^{+} / \mathrm{E}^{1} \Sigma^{+}$ & $10.5 / 29.5$ & $2558.20 / 219.40$ \\
\hline $\mathrm{E}^{1} \Sigma^{+} / \mathrm{F}^{1} \Sigma^{+}$ & $9 / 60$ & $425.78 / 12.07$ \\
\hline $\mathrm{F}^{1} \Sigma^{+} / \mathrm{G}^{1} \Sigma^{+}$ & $8.3 / 81.5$ & $302.22 / 63.36$ \\
\hline $\mathrm{G}^{1} \Sigma^{+} / \mathrm{H}^{1} \Sigma^{+}$ & 15.5 & 1799.033 \\
\hline $\mathrm{d}^{3} \Sigma^{+} / \mathrm{e}^{3} \Sigma^{+}$ & 7.5 & 1437.12 \\
\hline $\mathrm{e}^{3} \Sigma^{+} / \mathrm{f}^{3} \Sigma^{+}$ & 8.3 & 2958.29 \\
\hline
\end{tabular}




\begin{tabular}{|c|c|c|}
\hline $\mathrm{f}^{3} \Sigma^{+} / \mathrm{g}^{3} \Sigma^{+}$ & 6.9 & 277.85 \\
\hline $\mathrm{g}^{3} \Sigma^{+} / \mathrm{h}^{3} \Sigma^{+}$ & 5.9 & 426.66 \\
\hline
\end{tabular}

We plotted the PECS for the ground state $\mathrm{X}^{1} \Sigma^{+}$for all the alkali-metal hydrides $\mathrm{XH}$ systems (where $\mathrm{X}=\mathrm{Li}, \mathrm{Na}, \mathrm{Cs}, \mathrm{Rb}$, and $\mathrm{Fr}$ ) that are given in Figure 2, which are similar to the origin of energies attached to the limit $\mathrm{X}+\mathrm{H}(1 \mathrm{~s})$. In addition, their spectroscopic constants are presented in Table 4 with the accessible work found in the litterature ${ }^{\mathbf{1 6}, 88,89}$.

Table 4. Main spectroscopic constant for the ground state of the $\mathrm{XH}$ molecules ( $\mathrm{X}=\mathrm{Li}, \mathrm{Na}, \mathrm{K}, \mathrm{Rb}, \mathrm{Cs}$ and Fr).

\begin{tabular}{|c|c|c|c|}
\hline Molecules & References & $R_{e}$ (u.a.) & $\mathrm{D}_{\mathrm{e}}\left(\mathrm{cm}^{-1}\right)$ \\
\hline $\mathrm{LiH}$ & $\begin{array}{l}\operatorname{Ref}^{3} \\
\operatorname{Ref}^{17}\end{array}$ & $\begin{array}{l}3.003 \\
3.002 \\
\end{array}$ & $\begin{array}{l}20350 \\
20167 \\
\end{array}$ \\
\hline $\mathrm{NaH}$ & $\begin{array}{l}\operatorname{Ref}^{4} \\
\operatorname{Ref}^{88} \\
\operatorname{Ref}^{17} \\
\end{array}$ & $\begin{array}{c}3.507 \\
3.572 \\
3.54 \\
\end{array}$ & $\begin{array}{c}15489 \\
15970 \pm 403 \\
15671 \\
\end{array}$ \\
\hline KH & $\begin{array}{l}\operatorname{Ref}^{5} \\
\operatorname{Ref}^{88} \\
\operatorname{Ref}^{17}\end{array}$ & $\begin{array}{c}4.19 \\
4.265 \\
4.168\end{array}$ & $\begin{array}{l}14365 \\
14776 \\
14500\end{array}$ \\
\hline $\mathrm{RbH}$ & $\begin{array}{l}\operatorname{Ref}^{6} \\
\operatorname{Ref}^{\mathbf{8 8}} \\
\operatorname{Ref}^{17}\end{array}$ & $\begin{array}{l}4.40 \\
4.53 \\
4.395 \\
\end{array}$ & $\begin{array}{c}13940 \\
14599 \pm 565 \\
14099\end{array}$ \\
\hline $\mathrm{CsH}$ & $\begin{array}{l}\operatorname{Ref}^{7} \\
\operatorname{Ref}^{88} \\
\operatorname{Ref}^{16} \\
\operatorname{Ref}^{90} \\
\operatorname{Ref}^{17}\end{array}$ & $\begin{array}{c}4.47 \\
4.78 \\
4.7 \\
4.71 \\
4.464 \\
\end{array}$ & $\begin{array}{l}14879 \\
14809 \\
15083 \\
14791 \\
15019\end{array}$ \\
\hline FrH & This work & 4.43 & 14041 \\
\hline
\end{tabular}

As we can see in Figure 2 and Table 4, the profound wells are corresponding to the $\mathrm{LiH}^{\mathbf{1}}$ and $\mathrm{NaH}^{2}$ ones $\left(\mathrm{D}_{\mathrm{e}}=20350 \mathrm{~cm}^{-1}\right.$ and $15489 \mathrm{~cm}^{-1}$, respectively) whereas the well depths of $\mathrm{KH}^{3}$, $\mathrm{RbH}^{4}, \mathrm{CsH}^{5}$ and $\mathrm{FrH}$ are significantly smaller.

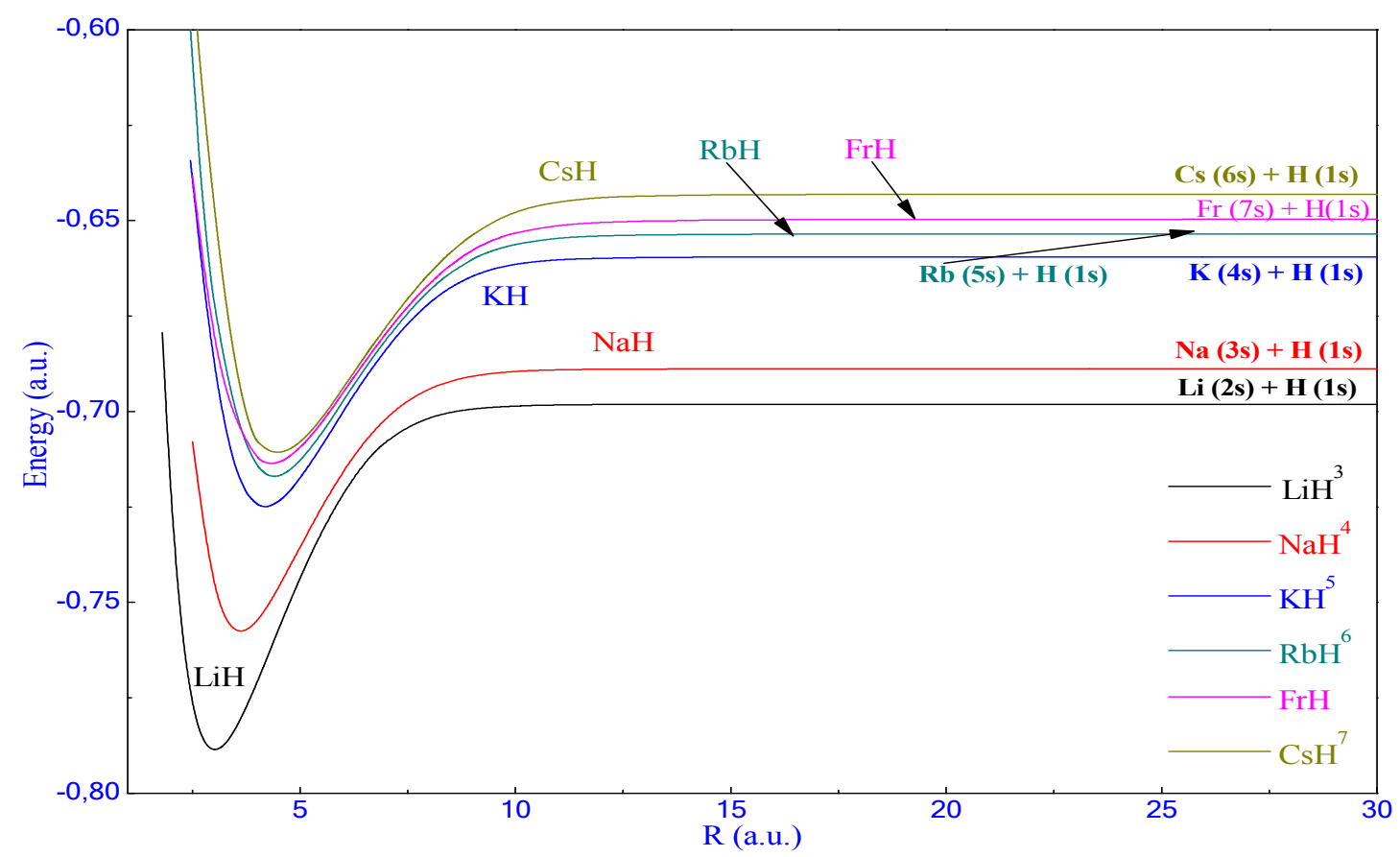


Figure 2. $\mathrm{X}^{1} \Sigma^{+}$adiabatic potential energy curves for $\mathrm{XH}(\mathrm{X}=\mathrm{Li}, \mathrm{Na}, \mathrm{K}, \mathrm{Rb}, \mathrm{Cs}$ and Fr). View Article Online

Note that for alkali metal atoms (Li-Cs), the smaller ionization potential (43 487, 41449,35 009, 33691 , and $31406 \mathrm{~cm}^{-1}$ ) is related to the heavier alkali atom and has the larger electron affinity (experimental values are 4984, 4403, 4043, 3920 and $3803 \mathrm{~cm}^{-1}$ for $\mathrm{Li}, \mathrm{Na}, \mathrm{K}, \mathrm{Rb}$ and $\mathrm{Cs}$, respectively $\left.{ }^{90}\right)$. Whereas, the ionization potential IP (Fr) $=32848 \mathrm{~cm}^{-1}$ exceeds the IP(Cs) by $1442 \mathrm{~cm}^{-1}$ and the EA $(\mathrm{Fr})^{91}=3678 \mathrm{~cm}^{-1}$ (see also' ${ }^{92}$ ) is larger by only $117 \mathrm{~cm}^{-1}$ than the one of Cs, nearly half-way between IP (Cs) and IP ( $\mathrm{Rb})$. Clearly, the mean error for the ionization potentials is $9 \mathrm{~cm}^{-1}$ and for excitation energies $20 \mathrm{~cm}^{-1}$. Especially for the heavier atoms, the electron affinities are less accurate, with errors from 4 to $9 \%$ for $\mathrm{K}, \mathrm{Rb}$, and $\mathrm{Cs}^{\mathbf{9 0}}$.

The PECS for all the ${ }^{1} \Sigma^{+}$states of the francium hydride have the same shape with the other alkali-metal hydrides (Li-Cs) $\mathrm{H}^{3-7}$.

In Figure 3, we have drawn the adiabatic potential curves for the eight ${ }^{3} \Sigma^{+}$states into the ionic limit $\mathrm{Fr}^{+}+\mathrm{H}^{-}$.

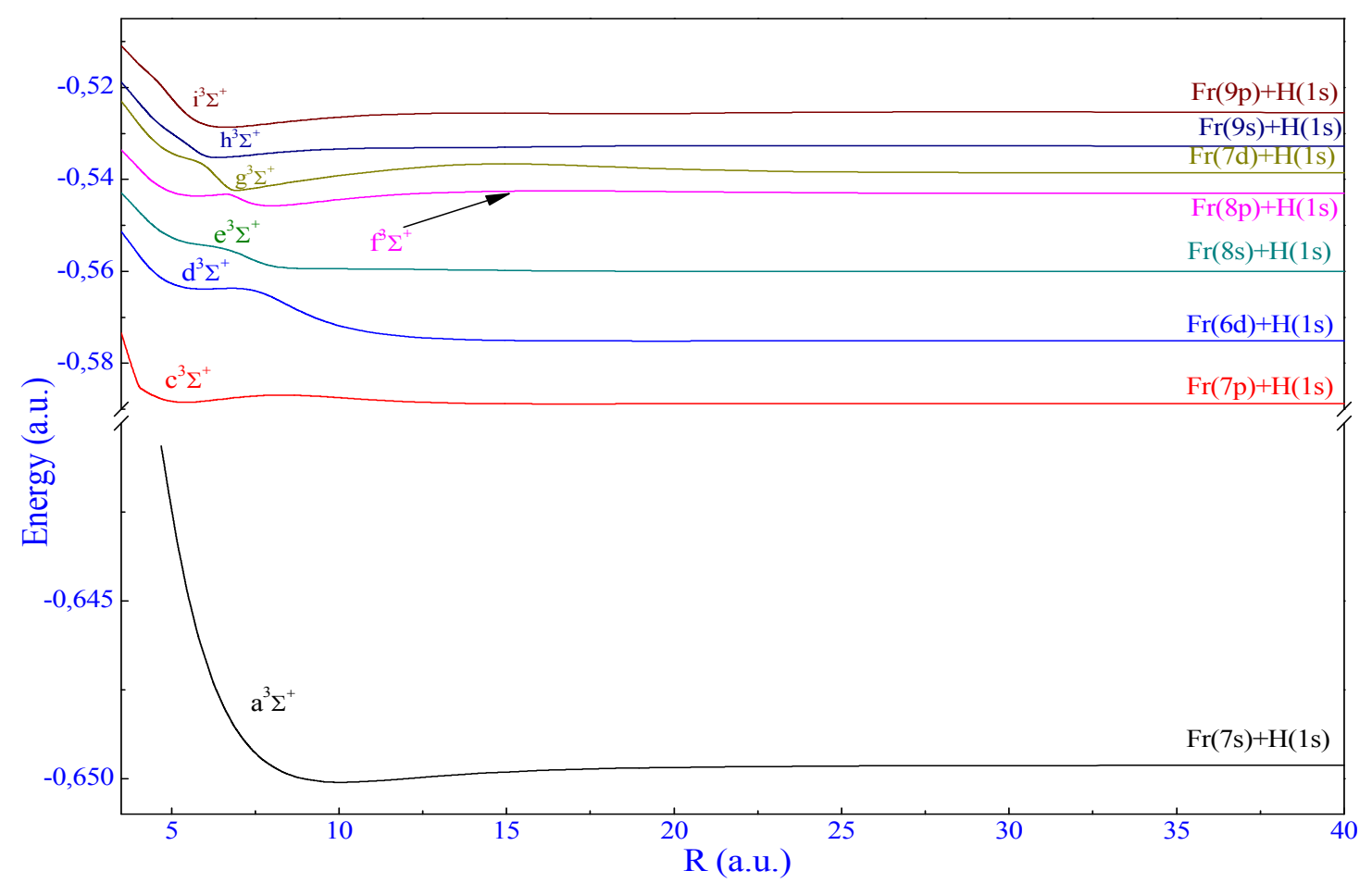

Figure 3. Eight adiabatic ${ }^{3} \Sigma^{+}$potential energy curves for the FrH molecule.

The first state $\mathrm{a}^{3} \Sigma^{+}$presents a shallow well at a remarkable large distance $\left(\mathrm{R}_{\mathrm{e}}=10.63\right.$ a.u. $)$, while the higher states (c, d, e and f) ${ }^{3} \Sigma^{+}$show two minima, the first one is between $R=5$ a.u and 6 a.u, the other one at large distance has as origin the existence of the ionic-neutral avoided crossing. The different avoided crossing positions are given in Table 3. As an example, we can 
see an avoided crossing between $\mathrm{f}^{3} \Sigma^{+}$and $\mathrm{g}^{3} \Sigma^{+}$states at $\mathrm{R}_{\mathrm{e}}=6.9$ a.u. which explaingsieth appearance of the double well depth for the $\mathrm{f}^{3} \Sigma^{+}$state.

Moving to the diabatic representation, we have displayed in Figures $\mathbf{4}$ and $\mathbf{5}$ the diabatic PECs for the ${ }^{1,3} \Sigma^{+}$states, which are named as $\mathrm{D}_{1-9}$ and $\mathrm{d}_{1-8}$, respectively.

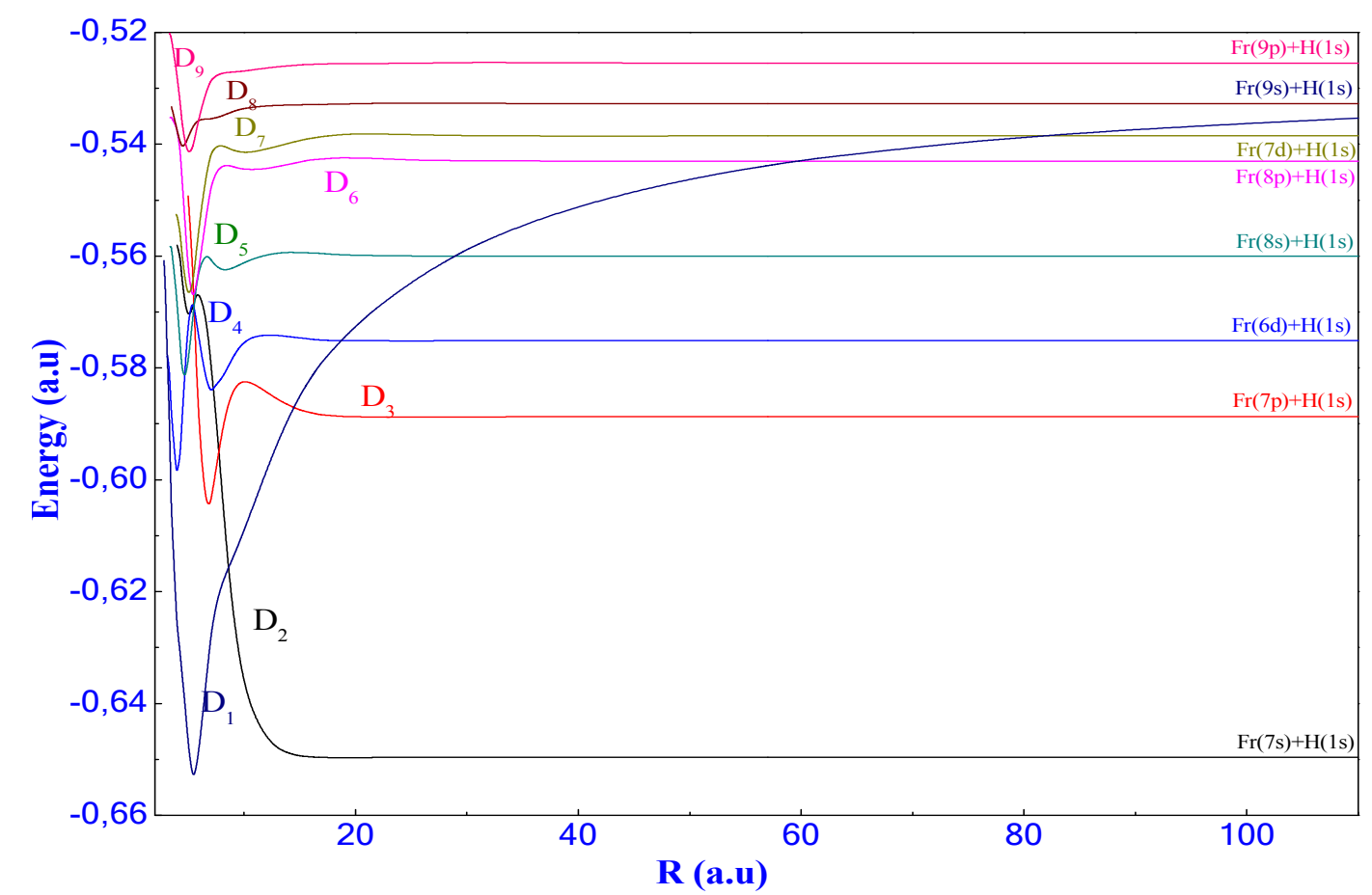

Figure.4. Diabatic ${ }^{1} \Sigma^{+}$potential energy curves dissociating below the ionic limit $\mathrm{Fr}^{+} \mathrm{H}^{-}$.

As we can see in the Figure 4, the avoided crossings in the adiabatic representation are changed into real crossings in the diabatic one. More clearly, the first diabatic PECs $\mathrm{D}_{1}$ corresponding to the $\mathrm{Fr}^{+} \mathrm{H}^{-}$ionic state crosses all the other states $\mathrm{D}_{2-9}$ at different distances and conducts as $2 / \mathrm{R}$ behaviour. Moreover, the other states show lower polarization and van der Waals interactions. Therefore, the same interpretation mentioned in $\mathrm{LiH}^{3}, \mathrm{NaH}^{4}, \mathrm{KH}^{5}, \mathrm{RbH}^{6}$ and $\mathrm{CsH}^{7}$, the lower states for the diabatic potential energy curves have strongly repulsive forms at short distance corresponding to the nature of Rydberg states, which can enlarged to large distances for the high-excited states. The diabatic state $\mathrm{D}_{2}$ crosses $\mathrm{D}_{3}$ at $\mathrm{R}=7.72$ a.u., $\mathrm{D} 4$ crosses $\mathrm{D}_{5}$ around 5.5 a.u. and $\mathrm{D}_{6}$ crosses $\mathrm{D}_{7}$ near 5.25 a.u. In addition, Figure 1 shows that the first diabatic ionic curve $\mathrm{D}_{1}\left(\mathrm{Fr}^{+} \mathrm{H}^{-}\right)$has a well depth at short distance $\mathrm{R}=5.5$ a.u. and crosses the $7 \mathrm{~s}$ state at about $8.5 \mathrm{a} . \mathrm{u}$, the $7 \mathrm{p}$ state approximately at $14.45 \mathrm{a}$.u. and the $7 \mathrm{~d}$ around at $18.65 \mathrm{a}$.u, also this curve crosses the higher states at very large distances. 
As we can see in Figure 5, the diabatic PECs of the ${ }^{3} \Sigma^{+}$states have the same interpretatidin of fle Online the diabatic PECs of the ${ }^{1} \Sigma^{+}$states.

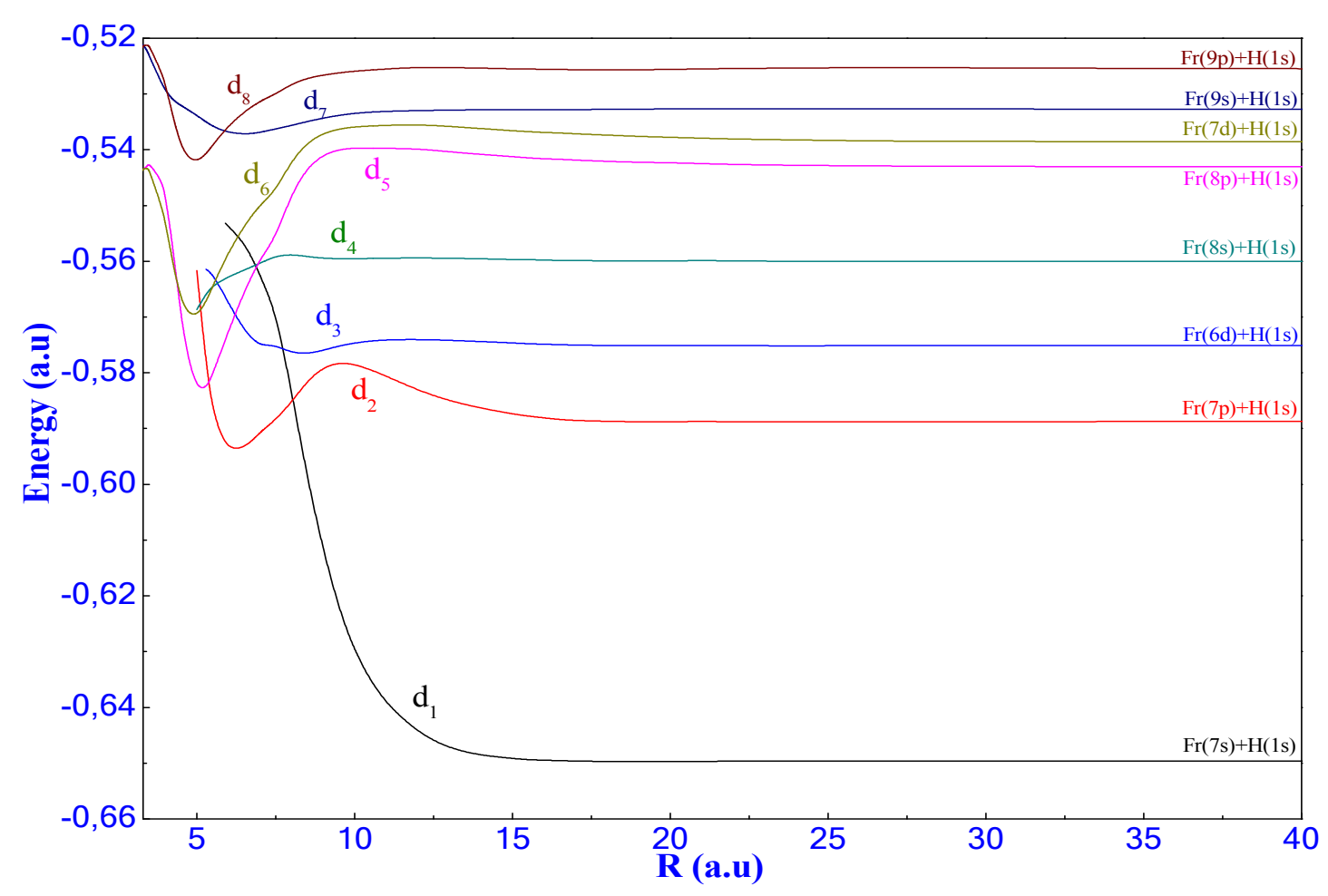

Figure.5. Diabatic ${ }^{3} \Sigma^{+}$potential energy curves dissociating below the ionic limit $\mathrm{Fr}^{+} \mathrm{H}^{-}$.

We note that the first diabatic ionic curve $\mathrm{d}_{1}\left(\mathrm{Fr}^{+} \mathrm{H}^{-}\right)$has a well depth at the distance $\mathrm{R}=10.8$ a.u. and crosses the states $7 \mathrm{p}, 6 \mathrm{~d}, 8 \mathrm{~s}, 8 \mathrm{p}$ and $7 \mathrm{~d}$ at about 8 a.u, 7.5 a.u, 6.8 a.u, 6.8 a.u and 6 a.u, respectively. As mentioned in the alkali hydride series ${ }^{1-5}$, we found that the interaction of the singlet states is strong with the possible charge transfer states, which are usually not present in triplet states. Furthermore, we can see that the lower ${ }^{3} \Sigma^{+}$diabatic states present a strong repulsive behavior at short distances like for ${ }^{1} \Sigma^{+}$ones. We note that, we observe the diabatic crossings between two successive states of ${ }^{3} \Sigma^{+}$like $d_{1}-d_{2}$ are almost the same positions than the related ${ }^{1} \Sigma^{+}$ones.

\subsection{The symmetries ${ }^{1,3} \Pi$ and ${ }^{1,3} \Delta$}

For $\Pi$ symmetry, the adiabatic PECS of $10^{1,3} \Pi$ for the francium hydride are presented in Figure $\mathbf{6}$ and their spectroscopic constants are displayed in Table 1 (c). Like for alkali-metal hydride ${ }^{1-5}$, the ${ }^{3} \Pi$ potential energy curves are a little deeper than ${ }^{1} \Pi$ ones. Indeed, these states reach speedily to their asymptotic limit at around $\mathrm{R}=20 \mathrm{a}$.u. Moreover, the $1^{3} \Pi$ have the deepest well 
at about 5.15 a.u and the potential depth De equals to $1620 \mathrm{~cm}^{-1}$. It should be noted that anleteficie Online states of $\Pi$ symmetry have a single well depth.

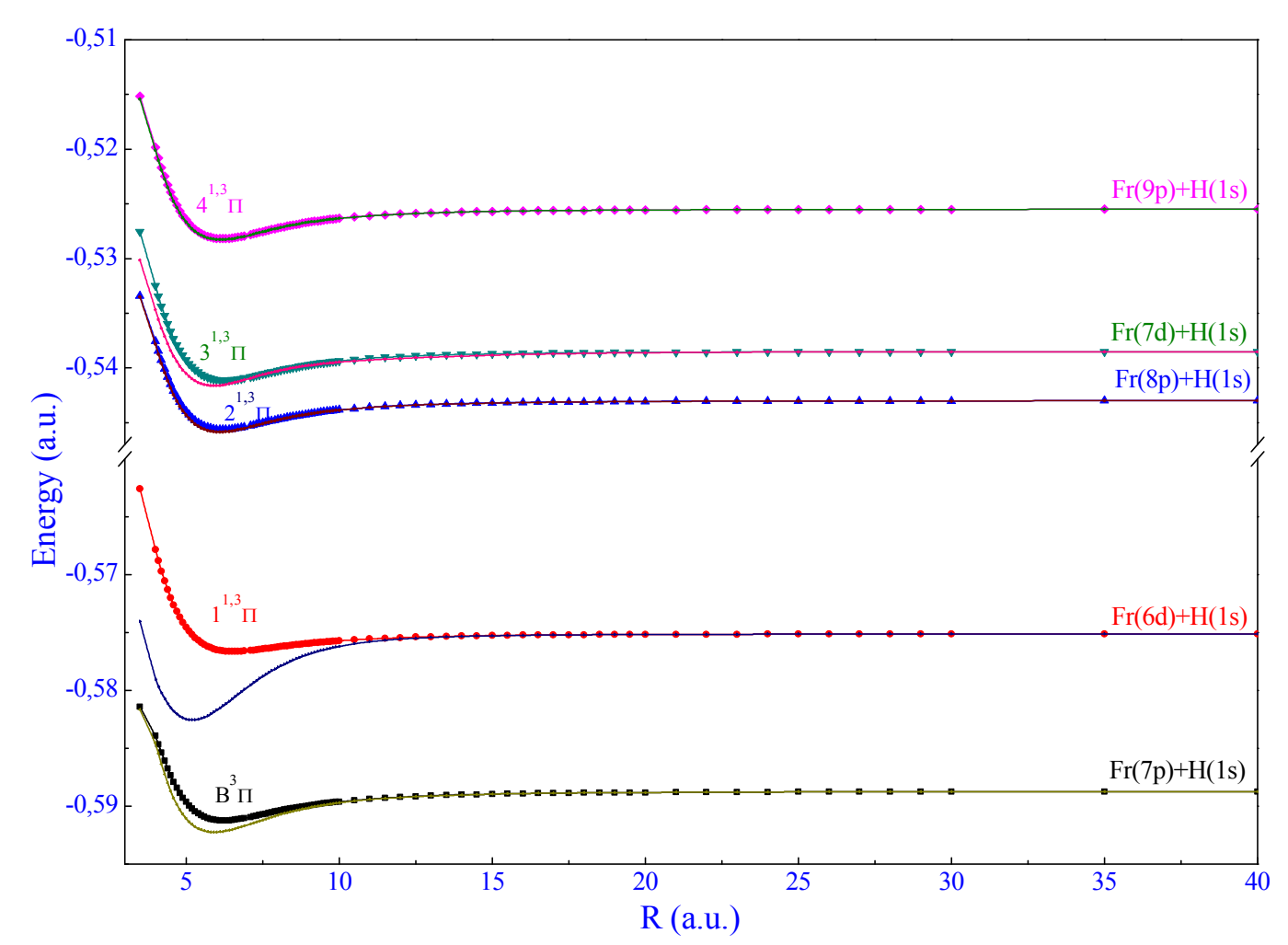

Figure 6. ${ }^{1,3} \Pi$ adiabatic potential energy curves for the $\mathrm{FrH}$ molecule.

Concerning the $\Delta$ symmetry, we have graphed the PECS of ${ }^{1,3} \Delta$ states in Figure S1 (Supporting Information) and their spectroscopic parameters are listed in Table 1(d). As usually observed for alkali-metal hydride ${ }^{3-7}$, the ${ }^{1} \Delta$ and ${ }^{3} \Delta$ PECS, which tend rapidly to the same limit, are nearly degenerated. Obviously, the first states $1^{1,3} \Delta$ have roughly the same value of the potential depth $\left(\mathrm{De}_{1}=460 \mathrm{~cm}^{-1}\right.$ and $\mathrm{De}_{2}=471 \mathrm{~cm}^{-1}$ for $1^{1} \Delta$ and $1^{3} \Delta$, respectively).

We have drawn in the diabatic representation the $\mathrm{PEC}_{S}$ for the symmetries ${ }^{1,3} \Pi$ in Figures 7 and for the ${ }^{1,3} \Delta$ symmetry in Figure S2 (Supporting Information). Interestingly, the Singlet and Triplet states of $\Pi$ and $\Delta$ symmetries are practically degenerate. As we can see in the Figures 6-7 and S1-S2, the curves of $\Pi$ and $\Delta$ symmetries show smooth variations and are quite similar in their behavior. However, we observe that the wells of the diabatic representation are somewhat less deep than the adiabatic ones. There are no avoided crossing that can be seen in the adiabatic $\mathrm{PEC}_{\mathrm{S}}$, which is related to the small non-adiabatic interaction. Except for the first diabatic state of the $\Pi$ symmetry crosses the second at around $\mathrm{R}=5 \mathrm{a}$.u. is because of the 
nearly avoided crossing in the adiabatic $\mathrm{PEC}_{\mathrm{S}}$. To sum up, the diabatic curves have not a stifontigcle online variation for the adiabatic one.

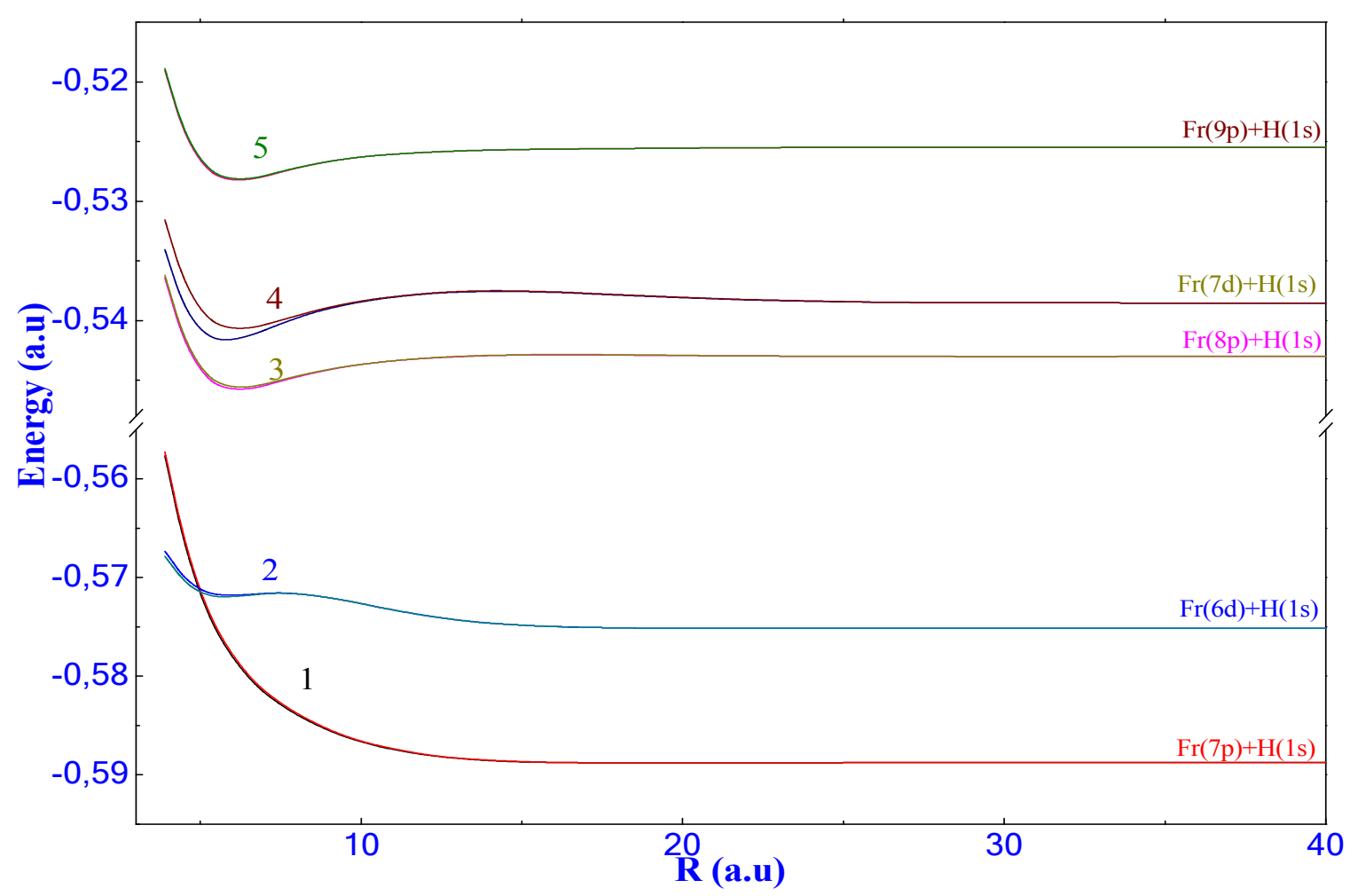

Figure.7. Diabatic ${ }^{1,3} \Pi$ potential energy curves dissociating below the ionic limit $\mathrm{Fr}^{+} \mathrm{H}^{-}$.

\section{Adiabatic and diabatic electric dipole moments}

\section{1.} Adiabatic and diabatic Permanent Dipole Moment

The adiabatic PDM from the symmetries ${ }^{1,3} \Sigma^{+}, 1,3 \Pi$ are reported in Figures 8-10 and for ${ }^{1,3} \Delta$ Symmetry in Figure S3 (Supporting Information). In fact, the PDM gives a direct picture of the ionic character in ${ }^{1} \Sigma^{+}$of the electronic wave function. This physical property has been shown in the alkali hydride series in the same symmetries [1-5]. Taken the work of the calcium hydride ion $\left(\mathrm{CaH}^{+}\right)^{65}$, the comportment of their PDM significantly can be a support for the identification of the various adiabatic electronic states below $\mathrm{Ca}^{2+}+\mathrm{H}^{-}$and $\mathrm{Ba}^{2+}+\mathrm{H}^{-}$, respectively. As we can see in Figure 8, the PDM functions of ${ }^{1} \Sigma^{+}$states vary slowly at the short internuclear distances, which is shown in the zoom of this figure whereas at large distances, they present abrupt variations. We notice that one after one; each adiabatic state leads to a maximum and after that drops to zero. In addition, these curves reproduce by piece the (-R) function like a linear behavior of the ionic state $\left(\mathrm{Fr}^{+}+\mathrm{H}^{-}\right)$and pass through forming nodes between successive pieces when combined. Moreover, the avoided crossings are very weak that explain the sharpness of 
the slopes around the crux of the dipole. Whereas, we have seen the same behavior in the dothericle Online alkali-metal hydride series ${ }^{3-7}$ whether, the avoided crossings in the potential energies curves and the crossings in the PDM figures were produced by the ionic curve.

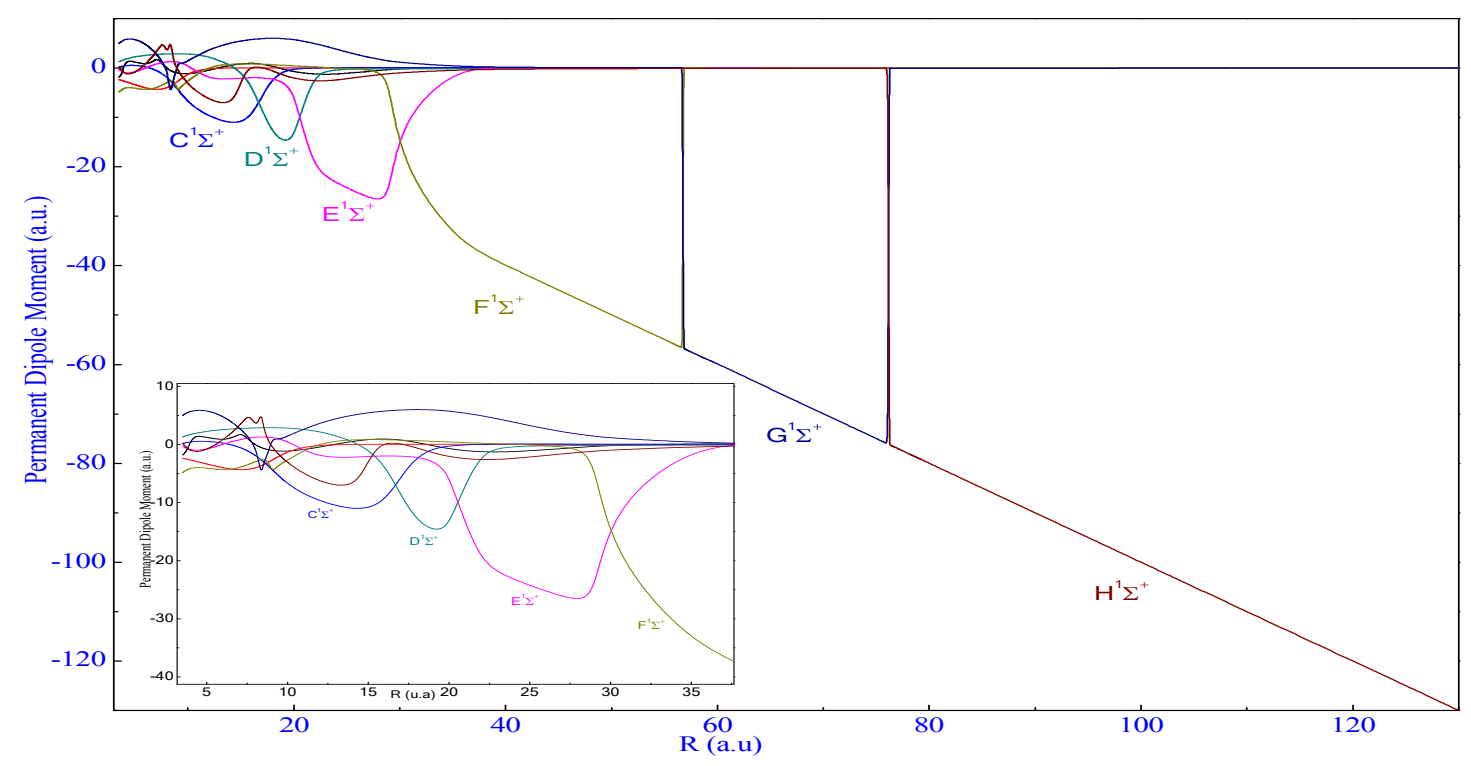

Figure 8. Permanent dipole moment for the ${ }^{1} \Sigma^{+}$states for the FrH with zoom for the PDM at short distance.

The important consequences of these crossings concern the efficiency of the charge transfer or the excitation, for instance, neutralization cross sections essentially relied on these crossing series, therefore, their important field for charge transfers in many astrophysical conditions $\mathbf{3}^{\mathbf{3 1}}$, 93-95. This physical property has been shown in the alkali hydride series in the same symmetries ${ }^{3-}$ 7 .

The Permanent Dipole Moment figures for ${ }^{3} \Sigma^{+}, 1,3 \Pi$ and ${ }^{1,3} \Delta$ are shown in Figures 9 and 10. Let us begin by the PDM curves for ${ }^{3} \Sigma^{+}$symmetry; Figure 9 indicates the significant variations at short distances before 20a.u. These functions are not negligible and have considerable influence on higher excited states. 


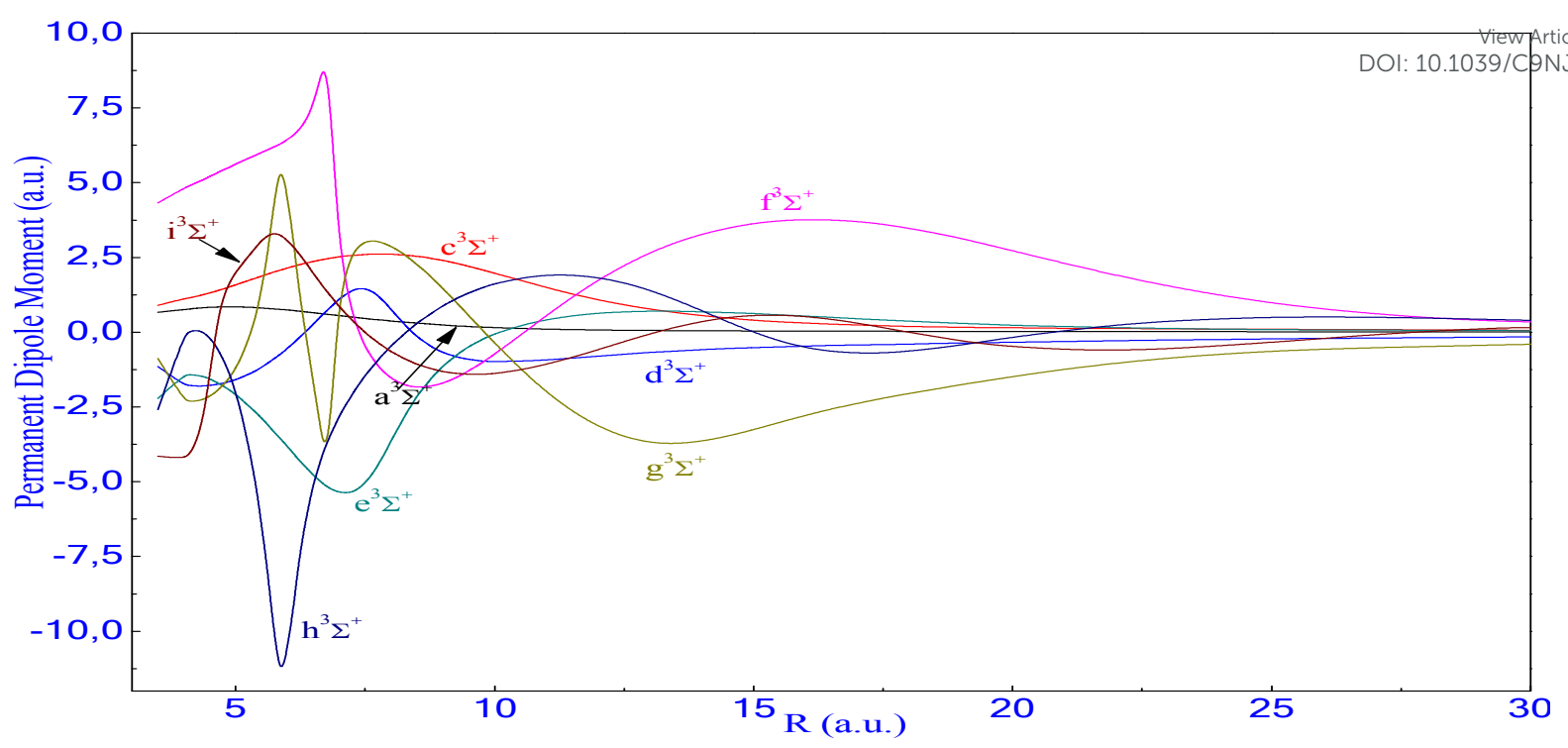

Figure 9. Permanent dipole moment for ${ }^{3} \Sigma^{+}$as a function of the internuclear distance for the FrH.

Then, they increase and vanish at a large distance. For instance, $\mathrm{h}^{3} \Sigma^{+}$and $\mathrm{g}^{3} \Sigma^{+}$states present maxima ( $\mu_{\max }=-11.58$ a.u. and -3.73 a.u.) respectively, at the distance $\mathrm{R}=5.9$ a.u. and 13.5a.u, respectively. Then it slowly decreases. These positions correspond to the avoided crossing in their potential energies curves. The PDM curves of symmetry ${ }^{1,3} \Pi$ show an important variation at short distances and tend rapidly to zero (see Figure 10).

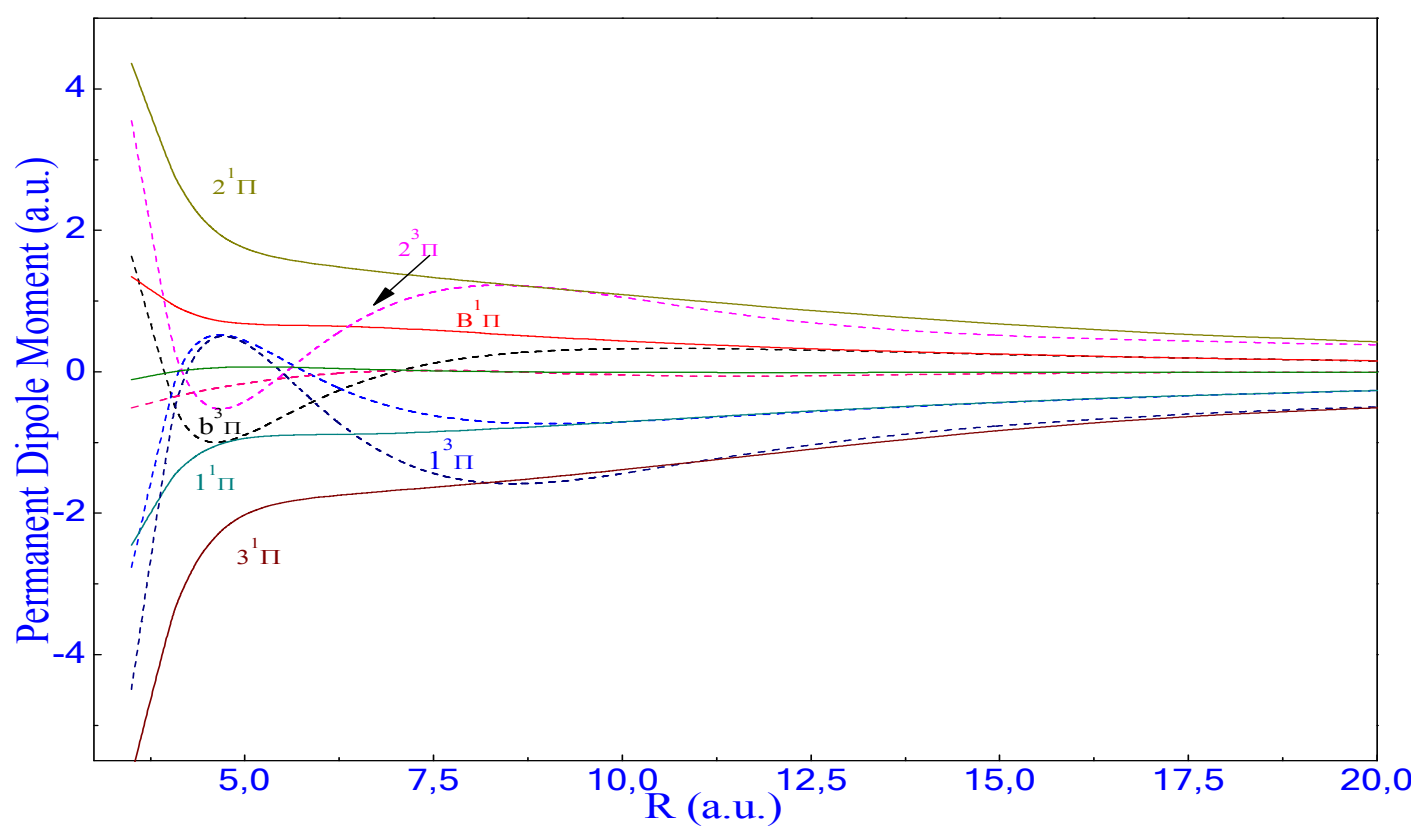

Figure 10. Permanent dipole moment for the ${ }^{1,3} \Pi$ states for the FrH.

In the Supporting Information (Figure S3), we observe that PDM functions of ${ }^{1} \Delta$ are identical to the ${ }^{3} \Delta$ ones, which explains the degeneracy in their PECs. 
Concerning the diabatic representation, the curves of the PDM are displayed in Figures 11 viand $_{\text {cle }}$ Online 12 for ${ }^{1,3} \Sigma^{+}$states.

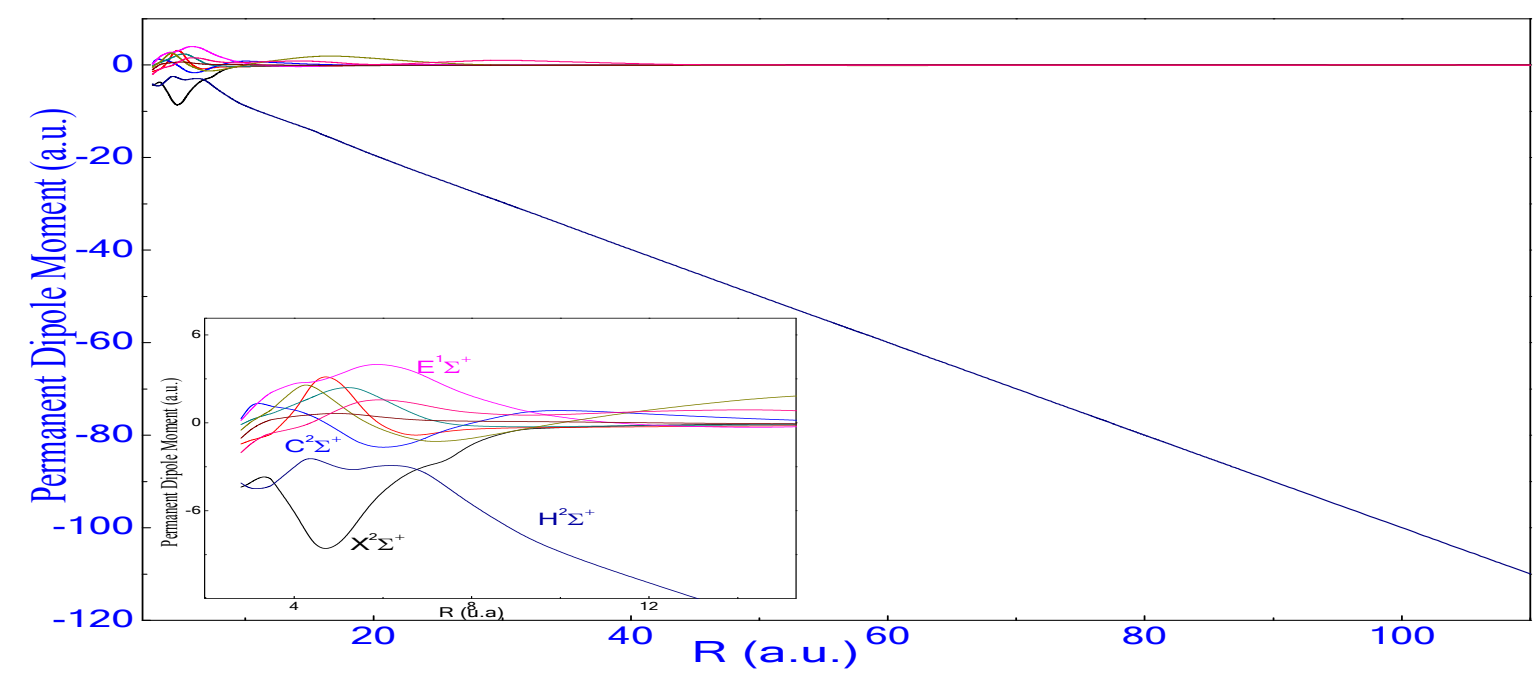

Figure.11. Permanent dipole moment for the ${ }^{1} \Sigma^{+}$diabatic states of FrH.

As shown for the all alkali hydride series ( $\mathrm{LiH}, \mathrm{NaH}, \mathrm{KH}, \mathrm{RbH}$ and $\mathrm{CsH})^{3-7}$, the diabatic PDM curves allow important information on these molecules. As we can see in Figure 11, we obtain a straight line, while the neutral diabatic dipole of the states decreases rapidly to zero when $\mathrm{R}$ increases. Interestingly, this simple shape reflecting the physics expected for the PDM of the various diabatic states is in uniformity with basic electrostatic considerations and gives strong support to the diabatisation method used.

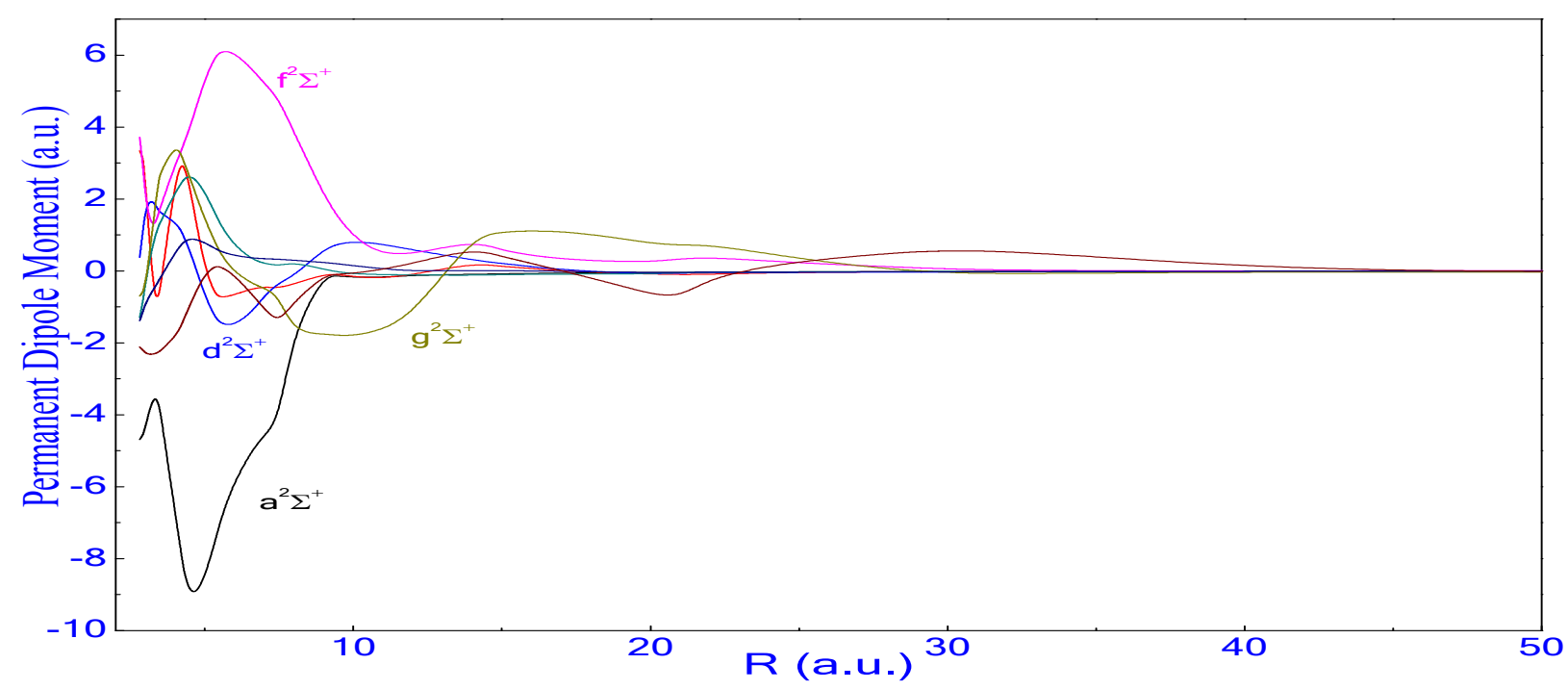

Figure.12. Permanent Dipole Moment for ${ }^{3} \Sigma^{+}$diabatic states of FrH.

\subsection{Adiabatic and diabatic TDM}


It is attractive to exemplify the curves of the TDM in the adiabatic and diabatic representationsticle online which help us to make the information for future photo-association experiments. The adiabatic curves have been presented in the Figures 12 and 13 for ${ }^{1} \Sigma^{+}$and ${ }^{3} \Sigma^{+}$, respectively, and they have been investigated for the first time.

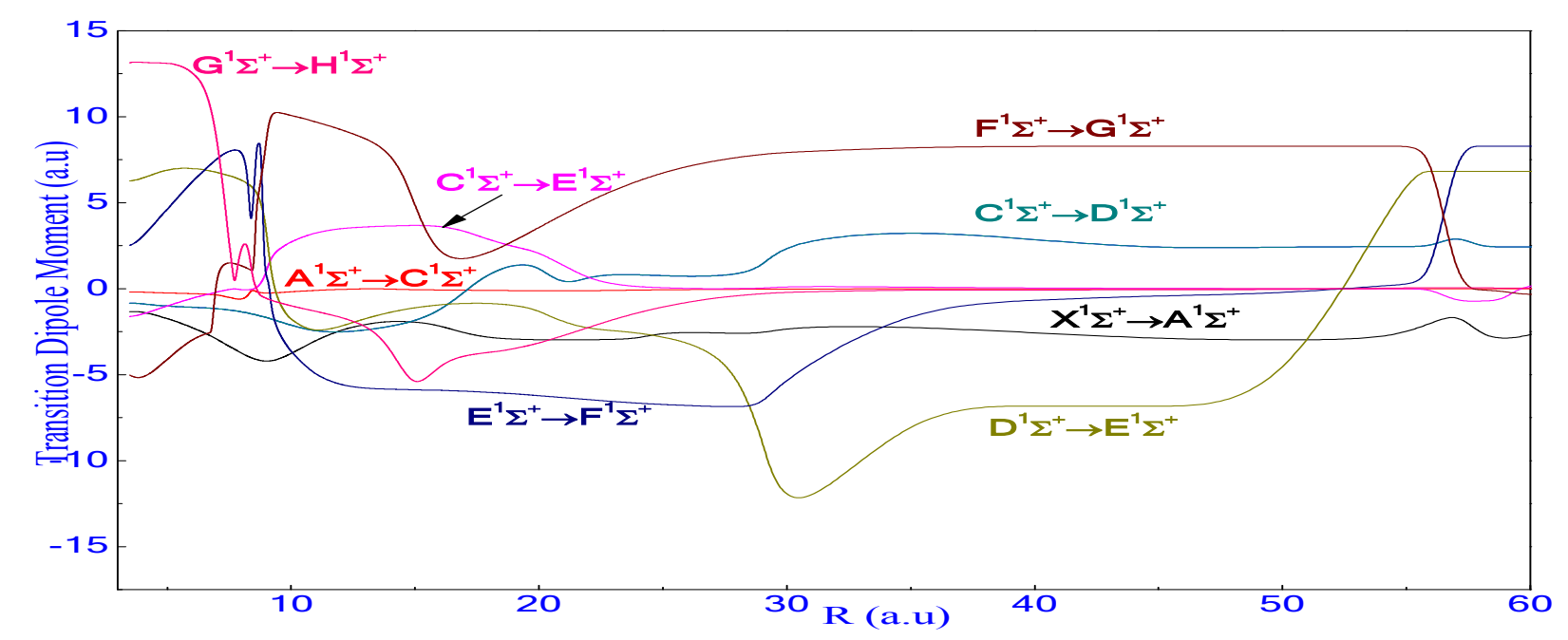

Figure 13. Transition dipole moment for selected excited states for symmetry ${ }^{1} \Sigma^{+}$.

We observe in the Figures 12 many peaks that are corresponding to the avoided crossings in the PECS at these distances. To explain more, the D-E TDM present a peak around 30 a.u. which corresponds to the avoided crossing between $\mathrm{D}$ and $\mathrm{E}$ electronic states. In addition, the large peak is detected for the E-F TDM curves, which correspond to the crossing of the E-F PECS at the distance 60 a.u. Interestingly, when the peak is higher and less wide, the avoided crossing was less compared to the A-C case. Similarly, the same remark is found in the work of the other alkali-metal hydride ${ }^{3-7}$. We have also conveyed in Figures 13 and 14 the TDM curves for symmetry ${ }^{1,3} \Sigma^{+}$. Noteworthy, most of the TDM curves do not have a peak, which is related to the repulsive shape in their PECS and the lack of the avoided crossing. Furthermore, the $(\mathrm{g}-\mathrm{h}){ }^{3} \Sigma^{+}$present clearly a peak at $\mathrm{R}=6.9$ a.u, which corresponds to the position of the avoided crossing between $\mathrm{g}$ and $\mathrm{h}$ states in their PECS. 


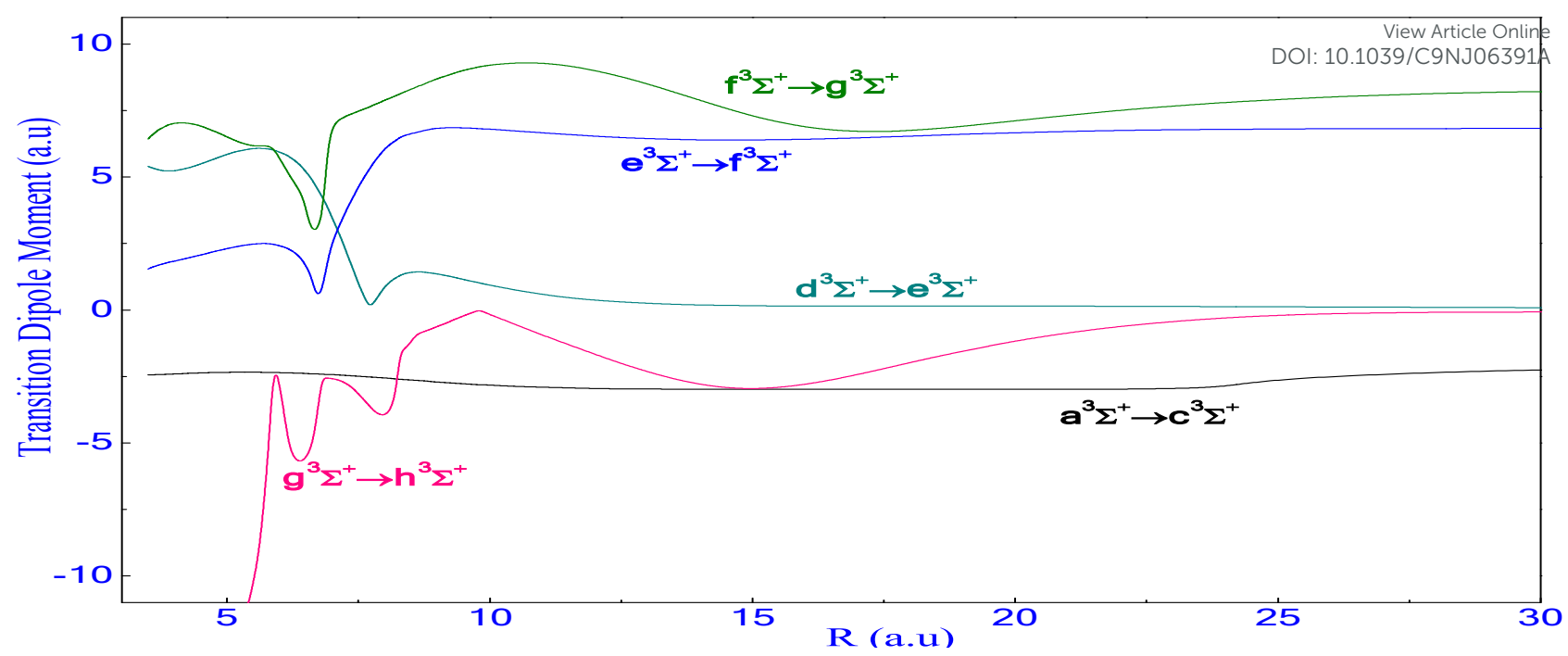

Figure 14. Transition dipole moment for selected excited states for symmetry ${ }^{3} \Sigma^{+}$.

In general, the corresponding avoided crossings in the PECs are then displayed around the large internuclear distances and the related maximum values in the TDM functions. Moreover, the most significant transitions which are between two successive states, for example, the transitions between $(\mathrm{F}-\mathrm{G}){ }^{1} \Sigma^{+}$and $(\mathrm{G}-\mathrm{H}){ }^{1} \Sigma^{+}$states are more important than the others.

Indeed, for the first time, we have investigated the diabatic curves of the TDM for the first state ${ }^{1} \Sigma^{+}$, which are showed in Figures S4 (Supporting Information). Furthermore, the diabatic curves show smoother variations of their physical characteristics at a short inter-nuclear distance while the adiabatic states present strong variations; it is difficult to pursue their physical acumen with a very limited number of states. As mention before, the avoided crossing in the adiabatic curves can be showed as peaks in their curves of TDM.

At large distances, the diabatic representation drops to zero and does not have any variation, while, in the adiabatic representation their variation continue to $\mathrm{R}=60$ a.u.

\section{Vibrational levels of FrH}

In this section, we have studied the spacing of the vibrational level for $1,3 \Sigma^{+}, 1,3 \Pi$ and $1,3 \Delta$ symmetries, for the first time. We have interpolated the vibrational levels by least-squares method (Numerov Program), which is written as following:

$$
E_{v}=V\left(R_{e}\right)+\omega_{e}\left(v+\frac{1}{2}\right)-\omega_{e} \chi_{e}\left(v+\frac{1}{2}\right)^{2}
$$

The NUMEROV program is prepared to determine the spectroscopic constants $\omega_{\mathrm{e}}$ and $\omega_{\mathrm{e}} \chi_{\mathrm{e}}$ from vibrational energy levels $G_{v}$. The equilibrium distance $R_{e}$ and $B_{e}$ are deduced at the minimum of the $V(R)$ potential. Since the vibrational wave functions can be calculated at the 
same moment for the two different electronic states, we can also get the quantities to reppressenticle Online the vibronic transition like an oscillator strength.

As shown in Figure 15, the adiabatic PECS for the (X, C, D) ${ }^{1} \Sigma^{+}$and their vibrational levels are plotted with their spacing's $\left(\mathrm{G}_{v^{-}} \mathrm{G}_{\mathrm{v}-1}\right)$ awarding to the vibrational levels' number $v$.
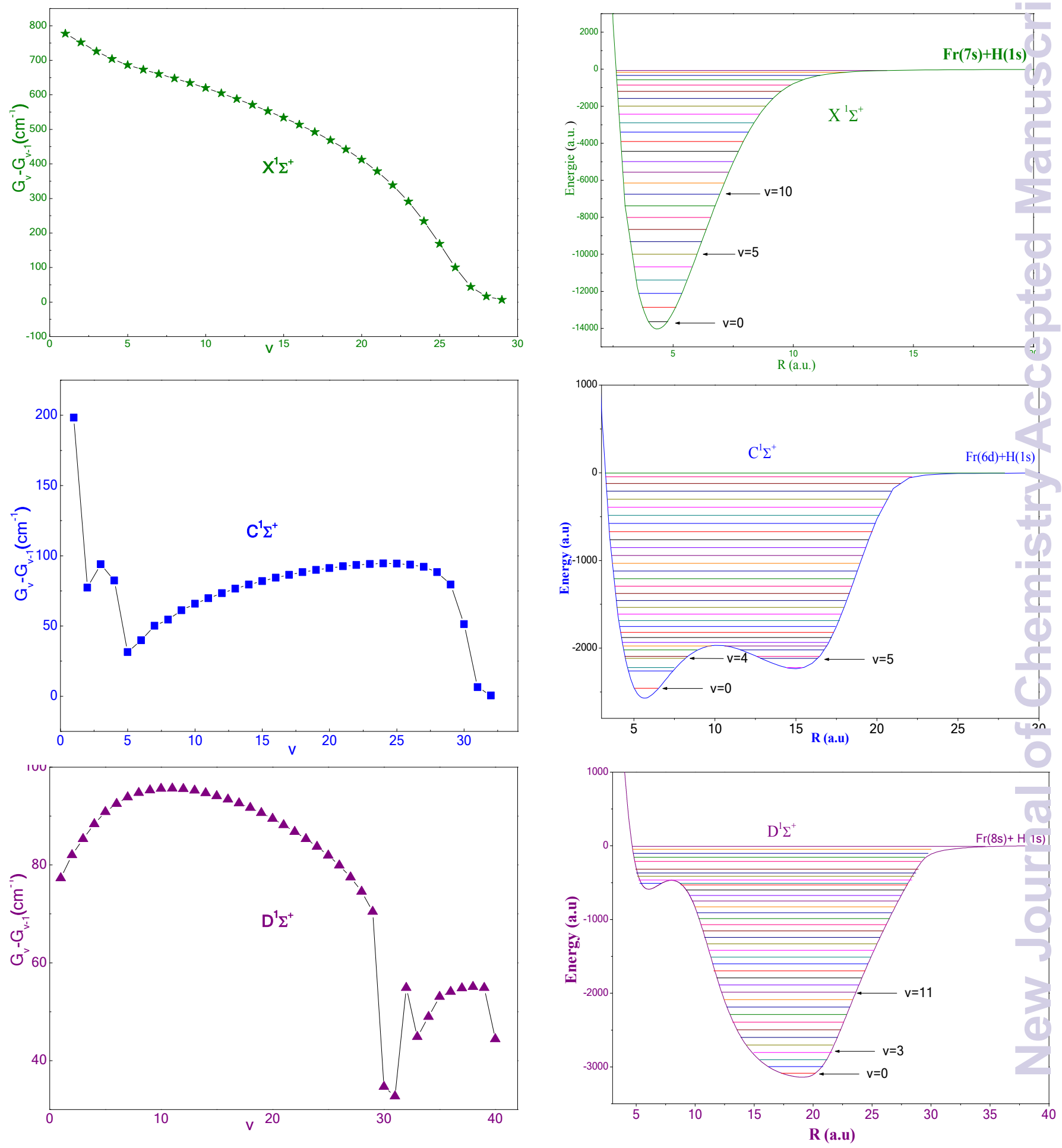
Figure 15. Vibrational spacing (left) and potential energy curves (right) for (X, C and D) ${ }_{D}^{1} \Sigma^{+}{ }_{10.1039 / C 9 N \mathrm{~N} 06391 \mathrm{~A}}^{+}$ FrH.

Therefore, $\mathrm{X}^{1} \Sigma^{+}$shows a deep potential well, which contains 27 vibrational levels. For the first vibrational levels, we observe a linear behavior reflecting an anharmonic form like Morse in their PECS. The spacing's become smaller and disappear at the dissociation limit (Fr (7s) + $\mathrm{H}(1 \mathrm{~s}))$. The same remark is applicable to the states that have a single well depth. The spacing for the $\mathrm{C}^{1} \Sigma^{+}$shows a sudden variation that indicates the presence of a second well. Then, we can see a slow variation from $v=3$ to $v=5$ considering that the second well is wider. It is worth noting that, accidental quasi-degeneracy appears one time $(v=4,5)$ and related to states, which are suitable to different wells. The $\mathrm{D}^{1} \Sigma^{+}$state has 41 vibrational levels which begin with an abrupt behavior up to $v=29$ then, a sudden change emerges from $v=30$ to $v=33$ reflecting a second wide anharmonic well.

In Figure 16, we have traced the vibrational level spacing for the other states of symmetries ${ }^{1} \Sigma^{+}$. The E, F and G states trap various vibrational levels and quasi-degeneracies corresponding to deep potential wells and the appearance of the second well. We notice that the $\mathrm{G}^{1} \Sigma^{+}$state has 146 vibrational levels, which are plentiful, and very tight, explained by the appearance of three depth wells.

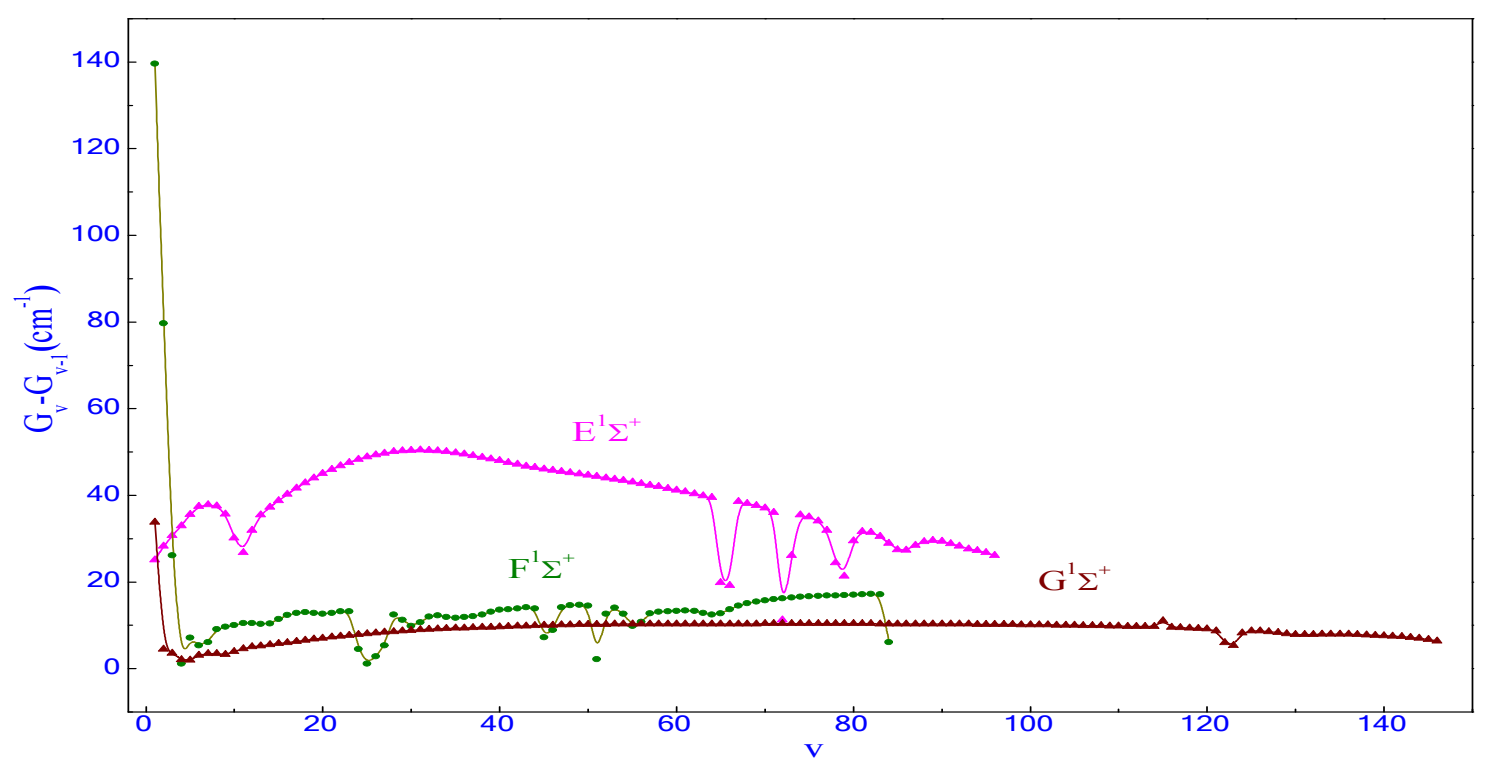

Figure 16. Vibrational level spacing for $(\mathrm{E}, \mathrm{F}$ and $\mathrm{G}){ }^{1} \Sigma^{+}$states of FrH.

We listed in Table 5 and 6, the vibrational levels for other states of ${ }^{3} \Sigma^{+},{ }^{1,3} \Pi$ and ${ }^{1,3} \Delta$ symmetries, which have a fewer vibrational level number. Therefore, that is explained by the repulsive shape in their potential curves. The most of these spacings are constant and linear; this is correlated with the anharmonicity of the potential wells. 
Table 5. Vibrational level spacing $\left(\mathrm{G}_{\mathrm{v}+1}-\mathrm{G}_{\mathrm{v}}\right)$ of $\left(\mathrm{a}, \mathrm{c}, \mathrm{f}\right.$, h and I) ${ }^{3} \Sigma^{+}$states (in $\left.\mathrm{cm}^{-1}\right)$. View Article Online

\begin{tabular}{|c|c|c|c|c|c|c|c|c|c|c|}
\hline V & \multicolumn{2}{|c|}{$\bar{~} \overline{a^{3} \Sigma^{+}}$} & \multicolumn{2}{|c|}{ " } & \multicolumn{2}{|c|}{$\mathrm{f}^{\mathrm{f}^{3} \Sigma^{+}}$} & \multicolumn{2}{|c|}{$\bar{~} \overline{\mathrm{h}^{3} \Sigma^{+}}$} & \multicolumn{2}{|c|}{$\mathrm{i}^{3} \Sigma^{+}$} \\
\hline & Energy & Spacing & Energy & Spacing & Energy & Spacing & Energy & Spacing & Energy & Spacing \\
\hline 0 & -89.99 & & -18.56 & & -482.68 & & -439.75 & & -585.79 & \\
\hline 1 & -51.45 & 38.54 & -5.02 & 13.54 & -288.90 & 193.78 & -251.17 & 188.58 & -397.58 & 188.21 \\
\hline 2 & -20.45 & 30.99 & -0.40 & 4.62 & -162.70 & 126.2 & -130.91 & 120.26 & -245.11 & 152.47 \\
\hline 3 & -8.06 & 12.4 & & & -74.53 & 88.17 & -69.31 & 61.6 & -128.77 & 116.34 \\
\hline 4 & -1.63 & 6.43 & & & -12.01 & 62.52 & -43.22 & 26.08 & -45.79 & 82.99 \\
\hline 5 & & & & & & & -15.67 & 27.56 & -11.17 & 34.62 \\
\hline 6 & & & & & & & & & -0.82 & 10.35 \\
\hline 7 & & & & & & & & & 14.48 & 15.3 \\
\hline 8 & & & & & & & & & 31.44 & 16.96 \\
\hline
\end{tabular}

As we can see in Table 5, the vibrational level of symmetry ${ }^{3} \Sigma^{+}$does not exceed eight levels and shows a linear behavior that is reflected the simple wells in their PECs. The same analysis for the symmetries ${ }^{1,3} \Pi$ and ${ }^{1,3} \Delta$ (see Table 6). More clearly, the vibrational levels of ${ }^{1} \Delta$ are roughly identical to the one for ${ }^{3} \Delta$ that is related to the degeneracy in their PECs. In summary, the spacing vibrational levels are investigated here for the first time for all symmetries and present important information considering the shape of the PECS.

Table 6. Vibrational-Level Spacing $\left(\mathrm{G}_{\mathrm{v}+1}-\mathrm{G}_{\mathrm{v}}\right)$ of ${ }^{1.3} \Pi$ and ${ }^{1.3} \Delta$ states (in $\left.\mathrm{cm}^{-1}\right)$.

\begin{tabular}{|c|c|c|c|c|c|c|c|c|c|c|c|c|}
\hline V & $\mathrm{B}^{1} \Pi$ & $1^{1} \Pi$ & $2^{1} \Pi$ & $3^{1} \Pi$ & $\mathrm{b}^{3} \Pi$ & $1^{3} \Pi$ & $2^{3} \Pi$ & $3^{3} \Pi$ & $1^{1} \Delta$ & $1^{3} \Delta$ & $2^{1} \Delta$ & $2^{3} \Delta$ \\
\hline 1 & 143.14 & 105.71 & 153.21 & 152.23 & 184.66 & 270.24 & 164.22 & 177.01 & 136.38 & 138.73 & 152.87 & 153.71 \\
\hline 2 & 113.25 & 73.01 & 121.01 & 120.47 & 156.93 & 258.03 & 131.41 & 135.66 & 100.79 & 103.35 & 120 & 120.02 \\
\hline 3 & 81.69 & 46.98 & 87.54 & 88.87 & 119.05 & 235.04 & 93.86 & 92.15 & 69.37 & 70.54 & 85.38 & 85.5 \\
\hline 4 & 56.7 & 24.32 & 60.61 & 61.63 & 86.34 & 203.64 & 62.31 & 62.64 & 41.72 & 43.05 & 57.42 & 57.46 \\
\hline 5 & 34.8 & 11.87 & 35.38 & 33.13 & 59.26 & 170.79 & 39.67 & 42.87 & 20.95 & 21.74 & 31.85 & 32.01 \\
\hline 6 & 21.09 & & 19.34 & 16.71 & 34.76 & 135.57 & 23.13 & 30.41 & 11.05 & 11.53 & 18.36 & 18.42 \\
\hline 7 & 10.27 & & & & 18.46 & 101.88 & 12.55 & 22.89 & & & & \\
\hline 8 & & & & & 10.42 & 67.21 & & & & & & \\
\hline 9 & & & & & & 24.82 & & & & & & \\
\hline 10 & & & & & & 12.79 & & & & & & \\
\hline
\end{tabular}

\section{Conclusion}

This study is an investigation of the diabatic and adiabatic electronic properties of $\mathrm{FrH}$ molecule, including PECs for all symmetries ${ }^{1,3} \Sigma^{+}, 1,3 \Pi$ and ${ }^{1,3} \Delta$, vibrational level spacing and the PDM and the TDM functions. The adiabatic calculation method is carried out in the BornOppenheimer approximation. The pseudo-potentials and the Full Configuration Interaction 
methods are applied here. Moreover, we have studied a diabatic study for this moleculev/ Frricle Online using the theory of the variational effective Hamiltonian combined to an active overlap matrix. The most striking result to emerge from the data is that the ${ }^{1} \Sigma^{+}$states show a significant series of avoided crossing. We observe that the highly potential part is related to the $\mathrm{Fr}^{+}+\mathrm{H}^{-}$ionic state similarly to the $\mathrm{XH}$ systems where $\mathrm{X}=\mathrm{Li}, \mathrm{Na}, \mathrm{K}, \mathrm{Rb}, \mathrm{Cs}^{3-7}$. These curves have the same behavior with the PECS of the other alkali-metal hydride. The PECs for the ${ }^{1,3} \Pi$ symmetries present a similar shape and for ${ }^{1} \Delta$ and ${ }^{3} \Delta$ are roughly identical.

The diabatic survey produces huge acumen into the strong interactions between the adiabatic states. From our results, we can see the ionic-neutral crossings at intermediate and large distances, exactly in the ${ }^{1} \Sigma^{+}$states. Moreover, the PDM functions show the appearance of $(-\mathrm{R})$ curve for the ionic limit $\left(\mathrm{Fr}^{+}+\mathrm{H}^{-}\right)$. The various crossings in PECs result from the unusual shapes with multiplicity wells that are related to the linear behavior in PDM curves and the peaks in TDM curves. More clearly, the PDM curves reproduce by piece the (-R) function like a linear behavior of the ionic state $\left(\mathrm{Fr}^{+}+\mathrm{H}^{-}\right)$and pass through forming nodes between successive pieces when combined. The important consequences of these crossings are for the photo-association and spontaneous emission or the radiative charge exchange ${ }^{31,94}$. In fact, the PDM functions give a direct explanation of the ionic character of the electronic wave function for FrH. These new results are very important for further theoretical and experimental researches, for example in spectroscopy ${ }^{96}$ or collision ${ }^{97-101}$ fields.

These diabatic results can be applied to calculate the vibronic shifts and radiatives as well as non-radiative lifetimes ${ }^{\mathbf{1 0 2 - 1 1 0}}$. In addition, inelastic collision cross sections studies could be made for instance for the process of charge transfer, which can be interesting for many fields in physics or maybe in astrophysics.

\section{Acknowledgments}

This research was funded by the Deanship of Scientific Research at Princess Nourah Bint Abdulrahman University through the research The Fast-track Research Funding Program. 


\section{References}

1J. G. Hill, K. A Peterson. J. Chem. Phys. 147, 244106 (2017).

${ }^{2}$ T. Noro, M. Sekiya, and T. Koga, Theor. Chem. Acc. 121, 289 (2008).

${ }^{3}$ F.X. Gadéa and T. Leininger, Theor. Chem. Acc. 116, 566-575 (2006).

${ }^{4}$ N. Khelifi, J. Phys. Chem. A, 113, 8425-8433 (2009).

${ }^{5}$ N. Khelifi, B. Oujia, and F. X. Gadea, J. Chem. Phys. 116, 2879 (2002).

${ }^{6}$ N. Khelifi, W. Zrafi, B. Oujia, and F. X. Gadea, Phys. Rev. A 65,042513 (2002).

${ }^{7}$ W. Zrafi, N. Khelifi, O. Brahim, and F. X. Gadea, J. Phys. B: At. Mol. Opt. Phys. 39, 3815 (2006).

${ }^{8}$ T. Noro, M. Sekiya, T. Koga, Theor Chem Acc 109,85 (2003).

${ }^{9}$ W. C. Stwalley and W. T. Zemke, J. Phys. Chem. Ref. Data 22, 87 (1993).

${ }^{10}$ V. M. Garcia, R. Caballol, and J. P. Malrieu, J. Chem. Phys. 109, 504 (1998).

${ }^{11}$ A. Boutalib and F. X. Gadea, J. Chem. Phys. 97, 1144 (1992).

${ }^{12}$ B. Lepetit, M. Le Dourneuf, J. M. Launay, and F. X. Gadea, Chem. Phys. Lett. 135, 377 (1987).

${ }^{13}$ F. X. Gadea and M. Pelissier, J. Chem. Phys. 93, 545 (1990).

${ }^{14}$ F. Gemperle and F. X. Gadea, J. Chem. Phys. 110, 11197 (1999).

${ }^{15}$ M. Dolg, Mol. Phys. 93, 141 (1996).

${ }^{16}$ P. Fuentealba, O. Reyes, H. Stoll, and H. Preuss, J. Chem. Phys. 87, 5338 (1987).

${ }^{17}$ M. Aymar, J. Deiglmayr and O. Dulieu, Can. J. Phys. 87, 543-556 (2009). 
${ }^{18}$ R. L. Stephen, W. B. Charles, and H. Partridge, J. Chem. Phys. 85 (9) (1986).

19J. Hooper, P. Baettig, and E. Zurek, J. Applied Phys. 111, 112611 (2012).

${ }^{20}$ G. Moritz, A. Wolf, and M. Reihera, J. Chem. Phys., 123, 184105 (2005).

${ }^{21}$ K. Boguslawski, P. Tecmer, G. Barcza, Ö. Legeza and M. Reiher,. Chem. Theory Comput. 9, 2959-2973 (2013).

${ }^{22}$ K. R. S. Chandrakumar* and Swapan K. Ghosh, Nano Letters Vol. 8, No. 1, 13-19 (2008).

${ }^{23}$ L. Yan; Y. Qu; C. Liu; J. Wang; R. J. Buenker, Ab Initio Many-Electron Study for the Low-Lying States of the Alkali Hydride Cations in the Adiabatic Representation. J. Chem. Phys., 136, 124304 (2012).

${ }^{24}$ M. Carnell; S. D. Peyerimhoff; B. A. Hess, Ab Initio MRDCI Calculations on the Cesium Hydride (CsH) Molecule. Z. Phys. D. At., Mol. Clusters, 333, 317-333 (1989).

25R. S. Ram and P. F. Bernath, J. Mol. Spectrosc. 283, 18 (2013).

26J. Zhang, L. Zhang, T. Cui, Y. Li, Z. He, Y. Ma, and G. Zou, Phys. Rev. B 75, 104115 (2007).

${ }^{27}$ G. Roma, C. M. Bertoni and S. Baroni, Solid State Commun. 98203 (1996).

${ }^{28}$ C. Crepin, J. Verges, and C. Amiot, Chem. Phys. Lett. 112, 10 (1984).

${ }^{29}$ R. W. Numrich and D. G. Truhlar, J. Phys. Chem. 79, 2745 (1975).

${ }^{30}$ G. D. Barrera, D. Colognesi, P. C. H. Mitchell and A. J. Ramirez-Cuesta, J. Chem. Phys. 317, 119 (2005).

${ }^{31}$ D. R. Stephens and E. M. Lilley, J. Appl. Phys. 39, 177 (1968).

${ }^{32}$ A.K. Belyaev, J. Grosser, J. Hahne, and T. Menzel. Phys. Rev. A, 60, 2151 (1999).

${ }^{33}$ A.K. Belyaev and P.S. Barklem. Phys. Rev. A, 68, 062703 (2003).

${ }^{34}$ C.M. Dutta, P. Nordlander, M. Kimura, and A. Dalgarno. Phys. Rev. A, 63, 022709 (2001).

${ }^{35}$ L. Mendez, I.L. Cooper, A.S. Dickinson, O. Mo, and A. Riera. J. Phys. B, 23, 2797 (1990).

${ }^{36}$ H. Croft, A.S. Dickinson, and F.-X. Gadéa. J. Phys. B, 32, 81 (1999).

${ }^{37}$ R. Curik and C.H. Greene. Phys. Rev. Lett. 98, 173201 (2007).

${ }^{38}$ B. Friedrich and D. Herschbach. J. Phys. Chem. A, 103,10280 (1999).

${ }^{39}$ P. Indelicato, P. J. Mohr, Theor. Chem. Acta 80, 207-214 (1991).

40J. A. Behr, S. B. Chahn, S. B. Dutta, A. Görlitz, A. Ghosh, G. Gwinner, L. A. Orozco, G. D. Sprouse and F. Xu Hyperfine Interact. 81197 (1993).

${ }^{41}$ M. A. Bouchiat and C. Bouchiat Rep. Prog. Phys. 601351 (1997).

${ }^{42}$ J. Zhang (张颕顽), M. Tandecki, R. Collister, S. Aubin, J. A. Behr, E. Gomez, G. Gwinner, L. A. Orozco, M. R. Pearson, and G. D. Sprouse Phys. Rev. Lett. 115, 042501 (2015).

${ }^{43}$ C. Fry and M. Thoennessen, Atomic Data and Nuclear Data Tables 99, 497-519 (2013). 
${ }^{44}$ J. P. Adolff, G. B. Kauffman, Francium (Atomic Number 87), the Last Discovered Natururafcle Online Element. Chem. Educ. 10, 387-394-1430-4171 (2005).

45J. E. Sansonetti, J. Phys. and Chem. Ref. Data, 36 497-507 (2007).

${ }^{46}$ L. H. Delmau, J. Moine, S. Mirzadeh and B. A. Mayer, J. Phys. Chem. B 117, 9258-9261 (2013).

${ }^{47}$ I. Budincevic, J. Billowes, M. L. Bissell, T. E. Cocolios, R. P. de Groote, S. De Schepper, V. N. Fedosseev, K. T. Flanagan, S. Franchoo, R. F. Garcia Ruiz, H. Heylen, K. M. Lynch, B. A. Marsh, G. Neyens, T. J. Procter, R. E. Rossel, S. Rothe, I. Strashnov, H. H. Stroke and K. D. A. Wendt, PHYS. REV. C 90, 014317 (2014).

48J. Singh Jaggi, S. V. SESHAN, M. R. MCDEVITT, G. SGOUROS, E. ,HYJEK, and D. A. SCHEINBERG, Int. J. Radia. Oncolo. Biol. Phys., 64, 1503-1512, (2006).

${ }^{49}$ M. Aymar, O. Dulieu and F. Spiegelman, J. Phys. B: At. Mol. Opt. Phys. 39, S905-S927 (2006).

${ }^{50}$ W. Kutzelnigg and W. Liu, J. Chem. Phys. 123, 241102 (2005).

${ }^{51}$ D. Peng and M. Reiher, Theor. Chem. Acc. 131, 1081 (2012).

52 L. Wenjian, Handbook of Computational Chemistry (2017).

${ }^{53}$ L.L.Foldy, SA. Wouthuysen On the Dirac theory of spin 1/2 particles and its nonrelativistic limit. Phys Rev 78:29 (1950).

${ }^{54}$ Douglas M, Kroll NM (1974) Quantum electrodynamical corrections to the fine structure of helium. Ann Phys 82:89

${ }^{55}$ W. Kutzelnigg, Relativistic one-electron Hamiltonians 'for electrons only' and the variational treatment of the Dirac equation. Chem Phys 225:203 (1997).

56 T. Nakajima, K. Hirao, J Chem Phys 113:7786 (2000).

57J. Deiglmayr, M. Aymar, R. Wester, M. Weidemüller, and O. Dulieu, J. Chem. Phys. 129, 064309 (2008).

${ }^{58} \mathrm{Ph}$. Durand, J. C. Barthelat, Theor. Chim. Acta, 38, 283 (1975).

${ }^{59} \mathrm{Ph}$. Durand, J. C. Barthelat, Chem. Phys. Lett., 27, 191 -194 (1974).

${ }^{60}$ H. Habli, H. Ghalla, B. Oujia, F. X. Gadea, Eur. Phys. J. D 64, 5 (2011).

${ }^{61}$ W. Gaied, H. Habli, B. Oujia, F. X. Gadea, Eur. Phys. J. D, 62, 371 (2011). ${ }^{62}$ W. Gaied, B. Oujia, Int. J. Nanoparticles, 3, 160 (2010).

${ }^{63}$ L. Mejrissi, H. Habli, H. Ghalla, B. Oujia, F. X. Gadea, J. Phys. Chem. A, 117, 5503 (2013).

${ }^{64}$ K. Abdesslem, L. Mejrissi, N. Issaoui, B. Oujia, F.X. Gadéa,J. Chem. Phys.36, 117, 89258938 (2013).

${ }^{65}$ H. Habli, R. Dardouri, B. Oujia, F.X. Gadéa. J. Chem. Phys. 115, 14045-14053 (2011). 
${ }^{66}$ M. Chaieb, H. Habli, L. Mejrissi, B. Oujia, and F. X. Gadea, J. Quantum Chem $114,73$. praticle Online 747 (2014).

${ }^{67}$ H. Habli, L. Mejrissi, N. Issaoui, S. J. Yaghmour, B. Oujia, and F. X. Gadea, Int. J. of Quantum Chem., 115, 172-186(2015).

${ }^{68}$ R. Guérout, M. Aymar, and O. Dulieu, Phys. Rev. A 82, 042508 (2010).

${ }^{69}$ R. Dardouri, K. Issa, B. Oujia and F. Xavier Gadéa, Int. J. of Quant. Chem. 112, 2724-2734 (2012).

${ }^{70}$ R. Dardouri, H. Habli, B. Oujia, F. X. Gadéa, Chem. Phys., 399, 65-79 (2012).

${ }^{71}$ N. Khémiri, R. Dardouri, B. Oujia, and F. X. Gadea, J. Phys. Chem. A. 117 8915-8924 (2013).

${ }^{72}$ R. Dardouri, H. Habli, B. Oujia, F.X. Gadéa. J. of Comp. Chem. 34, 2091-2099 (2013).

${ }^{73}$ N. Khelifi, B. Oujia, F.X. Gadea, J. of Phys. and Chem. Ref. Data. 36, 191-202 (2007).

${ }^{74}$ H. Habli, L. Mejrissi, H. Ghalla, S. J. Yaghmour, B. Oujia and F. X. Gadéa. Mol. Phys. 114, 1568-1582 (2016).

${ }^{75}$ S. Jellali, H. Habli, L. Mejrissi , M. Mohery, B. Oujia , F. X. Gadéa J. Mol. Phys. 114, 2910 (2016).

${ }^{76}$ H. Souissi, L. Mejrissi, H. Habli, At. A. Al-Ghamdi, B. Oujia, F. X. Gadea, Chem. Phys. 490, 19-28 (2017).

${ }^{77}$ H. Souissi, S. Jellali, M. Chaieb, H. Habli, B. Oujia and F. X. Gadéa, J. of Quan. Spect. \& Rad. Tran., 200, 173-189 (2017).

${ }^{78}$ Mtiri, S., Mejrissi, L., Habli, H., Al-Ghamdi, A.A., Oujia, B., Gadéa, F.X., Comput. and Theo. Chem. 1114, 15 33-46 (2017).

${ }^{79}$ R. Hamdi, K. Abdessalem, R. Dardouri, At. A Al-Ghamdi, B. Oujia and F. X. Gadéa, J. Phys. B: At. Mol. Opt. Phys., 51, 025004 (2017).

${ }^{80}$ W. Müller, J. Flesh, W. Meyer, J. Chem. Phys., 80, 3297 (1984).

${ }^{81}$ M. Foucrault, Ph. Millie, J. P. Daudey, J. Chem. Phys. 96, 1257 (1992).

${ }^{82}$ I. S. Lim, J. K. Laerdahl and P. Schwerdtfeger J. Chem. Phys. 116, 172 (2002).

${ }^{83}$ Yu. Ralchenko, A. Kramida, Reader J and NIST ASD Team 2011 NIST Atomic Spectra

Database (version 4.1). Available at: http://physics.nist. gov/asd/.

${ }^{84}$ F.X. Gadea, Phys. Rev. A. 36, 2557 (1987).

${ }^{85}$ F.X. Gadea, Phys. Rev A 431160 (1991).

${ }^{86}$ Romero,T.;Aguilar,A.;Gadea,F.X. J.Chem. Phys., 110, 16219 (1999).

${ }^{87}$ Gadea, F. X.; Kuntz, P. J. Mol. Phys., 63, 27 (1988).

${ }^{88}$ S R. Langhoff, C W Bauschlicher and H Jr Partridge, J. Chem. Phys. 85, 5158 (1986).

${ }^{89}$ W. C. Stwalley, W. T. Zemke and S. C. Yang, J. Chem. Ref. Data 20, 153 (1991). 
${ }^{90}$ E. Eliav, U. Kaldor and Y. Ishikawa, Phys. Rev. A 50 1121(1994).

91 E. Eliav, M. J. Vilkas, Y. Ishikawa and U. Kaldor J. Chem. Phys. 122, 224113 (2005).

${ }^{92}$ C. H. Greene Phys. Rev. A 42, 1405 (1990).

${ }^{93}$ A.S. Dickinson, R. Poteau, F.X. Gadea, J. Phys. B 32,5451 (1999).

${ }^{94}$ A.K. Belyaev, P.S. Barklem, A.S. Dickinson, F.X. Gadea, Phys. Rev. A 81, 032706 (2010).

${ }^{95}$ P.S. Barklem, A.K. Belyaev, A.S. Dickinson, F.X. Gadea, Astron. Astrophys. 519, A20 (2010).

${ }^{96}$ O.L. Malta, H.F. Britob, J.F.S. Menezesb, F.R. Gongalves e Silva, S. Alves Jr., F.S. Farias Jr., A.V.M. de Andrade, J. of Lumi. 75, 255-268 (1997).

${ }^{97}$ P. S. Barklem and P. J. O’Mara, Mon. Not. R. Astron. Soc. 311, 535 (2002).

${ }^{98}$ N. Zahzam, T. Vogt, M. Mudrich, D. Comparat, and P. Pillet, Phys. Rev. Lett. 96, 023202 (2006).

${ }^{99}$ P. Staanum, S. D. Kraft, J. Lange, R. Wester, and M. Weidemüller, Phys. Rev. Lett. 96, 023201 (2006).

${ }^{100}$ E. R. Hudson, N. B. Gilfoy, S. Kotochigova, J. M. Sage, and D. De Mille, Phys. Rev. Lett. 100, 203201 (2008).

${ }^{101}$ M. T. Hummon, T. V. Tscherbul, J. Klos, H.-I. Lu, E. Tsikata, W. C. Campbell, A. Dalgarno, and J. M. Doyle, Phys. Rev. Lett. 106, 053201(2011).

${ }^{102}$ F. Gemperle, F. X. Gadea, Europhys. Lett. 48, 513 (1999).

${ }^{103}$ A. Yiannopouplou, G. H. Jeung, H. S. Lee, Y. S. Lee, Phys. Rev. A. 59, 1178 (1999).

${ }^{104}$ T.V. Tscherbul, Buchachenko, A.A. New Journal of Physics .17, 1, (2015).

${ }^{105}$ A. S. Dickinson, F. X. Gadéa. Mont. Not. Roy. Astr. Soc. 318, 1227 (2000).

${ }^{106}$ H. Croft, A.S. Dickinson, F.X. Gadéa, Monthly Notices of the Royal Astronomical Society. 304, 327 (1999).

${ }^{107}$ Y .L. Huang, W. T. Luh, G. H. Jeung, F. X. Gadea, J. Chem. Phys. 113, 683 (2000).

${ }^{108}$ F.X Gadéa. T. Leininger. A.S. Dickinson. European Physical Journal D. 15, 251 (2001).

${ }^{109}$ C. Y. Wu, W. T. Luh, F. X. Gadéa, W. C. Stwalley. J. Chem. Phys. 128, 064303 (2008).

${ }^{110}$ R.F. Garcia Ruiz, R. Berger, J. Billowes, C.L. Binnersley, M.L. Bissell, A.A. Breier, A.J. Brinson, K. Chrysalidis, T. Cocolios, B. Cooper, K.T. Flanagan, T.F. Giesen, R.P. de Groote, S.Franchoo, F.P. Gustafsson......, Nuclear Theory, (2019). 
View Article Online DOI: 10.1039/C9NJ06391A 